Article

\title{
Influence of Thickness on Water Absorption and Tensile Strength of BFRP Laminates in Water or Alkaline Solution and a Thickness-Dependent Accelerated Ageing Method for BFRP Laminates
}

\author{
Yanlei Wang $\left.{ }^{1} \mathbb{(}\right)$, Wanxin Zhu ${ }^{1}$, Xue Zhang ${ }^{1, *}$, Gaochuang Cai ${ }^{2} \mathbb{C}$ and Baolin Wan ${ }^{3}$ \\ 1 State Key Laboratory of Coastal and Offshore Engineering, School of Civil Engineering, Dalian University of \\ Technology, Dalian 116024, China; wangyanlei@dlut.edu.cn (Y.W.); zhuwanxinpg@foxmail.com (W.Z.) \\ 2 Laboratoire de Tribologie et de Dynamique des Systèmes, Ecole Nationale d'Ingénieurs de \\ Saint-Etienne (ENISE), University of Lyon, UMR 5513, 58 Rue Jean Parot, \\ 42023 Saint-Etienne CEDEX 2, France; gaochuang.cai@enise.fr \\ 3 Department of Civil, Construction and Environmental Engineering, Marquette University, \\ Milwaukee, WI 53201, USA; baolin.wan@marquette.edu \\ * Correspondence: xuezhang@dlut.edu.cn; Tel.: +86-138-0408-9214
}

Received: 12 April 2020; Accepted: 20 May 2020; Published: 23 May 2020

check for updates

\begin{abstract}
This paper first presented an experimental study on water absorption and tensile properties of basalt fiber-reinforced polymer (BFRP) laminates with different specimen thicknesses (i.e., 1, 2, and $4 \mathrm{~mm}$ ) subjected to $60^{\circ} \mathrm{C}$ deionized water or alkaline solution for an ageing time up to 180 days. The degradation mechanism of BFRP laminates in solution immersion was also explored combined with micro-morphology analysis by scanning electronic microscopy (SEM). The test results indicated that the water absorption and tensile properties of BFRP laminates were dramatically influenced by specimen thickness. When the BFRP laminates with different thicknesses were immersed in the solution for the same ageing time, the water absorption of the specimens decreased firstly before reaching their peak water absorption and then increased in the later stage with the increase of specimen thickness, while the tensile strength retention sustaining increased as specimen thickness increased. The reason is that the thinner the specimen, the more severe the degradation. In this study, a new accelerated ageing method was proposed to predict the long-term water absorption and tensile strength of BFRP laminates. The accelerated factor of the proposed method was determined based on the specimen thickness. The proposed method was verified by test results with a good accuracy, indicating that the method could be used to predict long-term water absorption and tensile strength retention of BFRP laminates by considering specimen thickness in accelerating tests.
\end{abstract}

Keywords: basalt fiber-reinforced polymer (BFRP); thickness; durability; hygrothermal ageing; accelerated ageing method

\section{Introduction}

Fiber-reinforced polymer (FRP) composites such as Carbon FRP (CFRP), Glass FRP (GFRP) and Aramid FRP (AFRP) have been widely used in infrastructure construction and other fields [1-11]. However, large-scale applications of FRP composites in infrastructure construction are still limited for some reasons, e.g., high cost of CFRP and AFRP composites, poor chemical stability of GFRP composites [12-16]. Over the past few years, basalt fiber has gradually received more attention as a new inorganic green fiber for its environment-friendly features. The basalt fiber is made of basalt stone after melting at $1450-1500^{\circ} \mathrm{C}$. There is no pollution during its production process $[17,18]$. The basalt 
fiber has a greater elongation at break than carbon fiber, higher elastic modulus, and greater chemical stability than glass fiber, and lower cost than carbon fiber and aramid fiber [18-21]. Moreover, the basalt fiber is also a good flame retardant [21,22]. Therefore, basalt FRP (BFRP) composites are increasingly used in civil engineering, such as externally strengthening sheets of reinforced concrete (RC) structure. The literature $[23,24]$ revealed that BFRP laminates would be degraded due to the strong alkaline environment inside concrete $(\mathrm{pH}=12-13)$, and such degradation would be further accelerated when the BFRP laminates were exposed to hygrothermal environments. The reason is that the resin matrix of BFRP laminates is highly sensitive to the change of the temperature and the moisture [25-27], which is seriously harmful to BFRP laminates. Therefore, the hygrothermal ageing properties of BFRP laminates in alkaline solution need to be studied.

At present, some researches [28-32] have been done on the hygrothermal ageing properties of BFRP laminates subjected to alkaline solution. Lu et al. [28,29] investigated the long-term mechanical properties of pultruded BFRP laminates after a long-term immersion. The test results showed that as the increase of immersion time, the water absorption increased, and the tensile strength and interlaminar shear strength decreased dramatically due to the severe interfacial debonding between the basalt fiber and resin matrix after ageing. Ma et al. [30] tested the tensile strength of BFRP laminates fabricated by the vacuum assistant resin infusion (VARI) method. The tensile strength of BFRP specimens decreased by $37 \%$ and $34 \%$ at $20^{\circ} \mathrm{C}$ and $40{ }^{\circ} \mathrm{C}$ for distilled water and decreased by $67 \%$ and $90 \%$ for alkaline solution after 180 ageing days, respectively. Xiao et al. [31] studied the tensile properties of wet-layup BFRP laminates. After immersion of 180 ageing days, it was observed that a higher temperature (e.g., 60 or $80^{\circ} \mathrm{C}$ ) would cause a greater reduction of tensile strength during the same ageing time. Wu et al. [32] studied the degradation of basalt fiber and BFRP laminates and concluded that the tensile properties of BFRP laminates were superior to that of basalt fiber in alkaline solution. The tensile properties reduction of BFRP laminates might be attributed to the severe degradation of interfacial adhesion between the basalt fiber and epoxy resin, which was observed by scanning electron microscopy (SEM) images, rather than the ageing of basalt fibers. It can be concluded from the existing studies that the long-term mechanical properties of BFRP laminates were greatly affected by the hygrothermal environment. A higher temperature and alkaline solution would aggravate the ageing process, leading to a severe interfacial debonding between the basalt fiber and resin matrix.

Although the above researches showed that the hygrothermal ageing properties of BFRP laminates have been studied by many test methods, the long-term durability of BFRP laminates still cannot be evaluated comprehensively. One reason is that different specimen thicknesses (ranging from 0.45 to $4.5 \mathrm{~mm}$ ) were adopted for test specimens in the existing researches [21,28,30-33]. For example, Lu et al. [28] measured the water absorption of BFRP specimens with a thickness of $1.4 \mathrm{~mm}$, which were immersed in $60^{\circ} \mathrm{C}$ distilled water, and found that water absorption was $0.32 \%$ after 90 days of ageing. Xiao et al. [31] also immersed the BFRP specimens with a thickness of $1.0 \mathrm{~mm}$ in the $60^{\circ} \mathrm{C}$ distilled water for the same ageing time (i.e., 90 days), while the water absorption of the specimens was $2.8 \%$. Lu et al. [29] studied the tensile properties of the BFRP laminates with a thickness of $1.4 \mathrm{~mm}$ in alkaline solution. After ageing for 90 days, the tensile strength retention of the BFRP laminates decreased to $71.9 \%, 61.1 \%$, and $56.8 \%$, respectively, at 20,40 , and $60^{\circ} \mathrm{C}$. As reported by Xiao et al. [31], the tensile strength retention of $1.0 \mathrm{~mm}$ thickness BFRP laminates decreased to $77.3 \%, 33.3 \%$, and $40.8 \%$ after the immersion in alkaline solution for 90 days. It can be seen from the above studies that although the same hygrothermal ageing tests were conducted for BFRP laminates, the test results cannot be compared directly due to the difference of specimen thickness. It has been reported that the durability test results of FRP composites were probably dependent on the dimensions of the adopted specimen. For example, the influence of diameter on the long-term durability of FRP bars was previously investigated [34,35]. According to the existing test results [34,35], for the same ageing time, the deterioration degree of BFRP bars was inversely related to the diameter of the specimen, which means that the specimen dimension should not be neglected on exploring the durability of BFRP composites. Therefore, the investigation 
of the influence of specimen dimension (especially specimen thickness) on long-term durability of BFRP laminates was very necessary.

Additionally, the ageing time adopted in above hygrothermal ageing tests was much shorter than the actual service duration of FRP composites, meaning that these test results were unsuitable to evaluate the long-term performances. Therefore, some efforts have been made to explore test methods to accelerate the ageing process of FRP composites. So far, the temperature-dependent accelerated ageing method was widely adopted in hygrothermal ageing tests $[36,37]$. The efficiency of the accelerated test is highly dependent on the accelerated factor, which is determined by experimental parameters. For example, the accelerated factor of temperature-dependent acceleration is calculated by considering at least three ageing temperatures in the test. In theory, the greater accelerated effect could be achieved by using higher test temperatures. However, the accelerated efficiency of temperature-dependent acceleration for FRP composites was not improved significantly because the adopted ageing temperature must be lower than the glass transition temperature $\left(T_{g}\right)$ of FRP composites [36]. The excessive ageing temperature would change the resin matrix of FRP composites from glassy to viscous fluid status, deteriorating the properties severely and changing the ageing mechanism. To this end, it is significant to explore alternative accelerated ageing methods for which the aforementioned limitation should be solved.

In this paper, the influence of specimen thickness on the water absorption behavior and tensile properties of BFRP laminates in $60^{\circ} \mathrm{C}$ deionized water and alkaline solution were first experimentally investigated. Through analyzing and summarizing the rules between the specimen thickness and the test results, an accelerated ageing method dependent on specimen thickness was proposed for the water absorption and tensile strength of BFRP laminates. Two accelerated ageing factors were theoretically established considering specimen thicknesses for water absorption and tensile strength of BFRP laminates, respectively. The test results were also adopted to verify the accuracy of the proposed method. The proposed accelerated ageing method in this study provides a new way for the prediction of the long-term ageing properties of BFRP laminates, which is simple and easy to apply.

\section{Materials and Methods}

\subsection{Materials and Laminates Fabrication}

Commercial unidirectional basalt fiber fabric (purchased from Aerospace Tuoxin Basalt Industrial Co., Ltd., Chengdu, China) with an areal density of $300 \mathrm{~g} / \mathrm{m}^{2}$ and a nominal thickness of $0.16 \mathrm{~mm}$ was adopted in the current study. Epoxy main agent and curing agent (Model JGN-T, produced by Kaihua New Technology Engineering Co., Ltd., Dalian, China) with a weight ratio of 3:1 were used as the matrix of BFRP laminates. It is one kind of commercial epoxy resin commonly used in FRP strengthening engineering in China [38]. No other fillers were added in the matrix except those added by the manufacturer. The mechanical parameters of the basalt fiber fabric and epoxy resin were provided by the corresponding manufacturers as shown in Table 1.

Table 1. Mechanical properties of materials.

\begin{tabular}{cccc}
\hline Material & Tensile Strength (MPa) & Elastic Modulus (GPa) & Elongation at Break (\%) \\
\hline Basalt fiber fabric & 2100 & 91 & 2.6 \\
Epoxy resin & $>40$ & $>2.5$ & $>1.8$ \\
\hline
\end{tabular}

BFRP laminates used in the current study were fabricated using wet lay-up method. The fiber direction of basalt fabrics was properly stacked to ensure that the unidirectional BFRP laminates were fabricated. The laminates with specific number of fabric layers (i.e., 2, 4 , and 8 layers) were fabricated. Specially designed molds with the thickness $h=1, h=2$, and $h=4 \mathrm{~mm}$ to fabricate the laminates need to be used to ensure the required thickness of the laminates. The fiber volume fraction of the BFRP 
laminates was 0.32. In this paper, BFRP laminates with the thickness $h=1, h=2$, and $h=4 \mathrm{~mm}$ were represented with $\mathrm{B}_{1}, \mathrm{~B}_{2}$, and $\mathrm{B}_{4}$, respectively.

\subsection{Water Absorption Test}

According to ASTM D5229 [39], the water absorption specimens were subjected to deionized water and alkaline solution $(\mathrm{pH}=13)$ at a temperature of $60^{\circ} \mathrm{C}$ for a duration of 180 days. The setting $\mathrm{pH}$ of the alkaline solution is 13 , which was used to simulate the pore water of the concrete [40]. The square specimens of water absorption (shown in Figure 1a) were cut from the fabricated BFRP laminates, and the dimensions of the specimens were $60 \times 60 \times h \mathrm{~mm}$, where $h$ represents the thickness of the BFRP laminates. The initial dry weight $\left(W_{0}\right)$ of the specimen was weighed using a precision electronics balance (Model FA2004N, Shanghai Precision Scientific Instruments Co., Ltd., Shanghai, China) with an accuracy of $0.1 \mathrm{mg}$ before immersion. After specific immersion time, the wet specimen was re-weighed. Before re-weighing, the water on the surface of the specimen was wiped using absorbent paper. The water absorption $M(t)$ at specific ageing time is calculated by Equation (1). Ten specimens for each thickness were tested and the average values and standard deviation of water absorption for each thickness at specific immersion time were calculated.

$$
M(t)=\left(\frac{W_{t}-W_{0}}{W_{0}}\right) \times 100 \%
$$

where $W_{\mathrm{t}}$ is the weight of wet specimen at specific ageing time $t$.

(a)

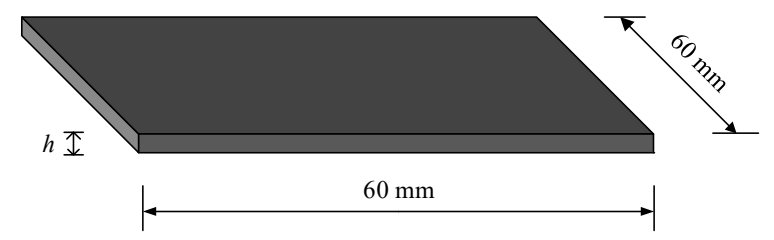

(b)

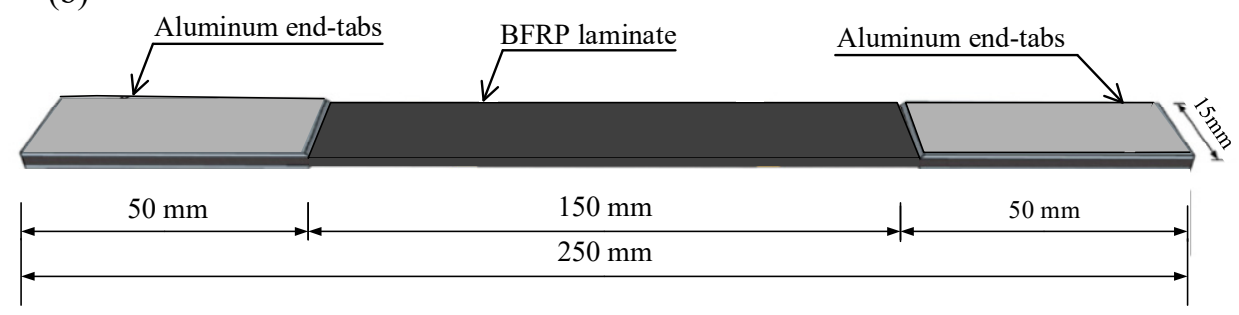

Figure 1. Test specimens of BFRP laminates. (a) water absorption test and (b) tensile test.

\subsection{Tensile Test}

The requirements for the tensile test of BFRP laminates were conducted in accordance with ASTM D3039 [41]. The rectangular tensile specimens with the dimensions of $250 \times 15 \times h \mathrm{~mm}$ (shown in Figure 1b) were cut from the fabricated BFRP laminates, which were soaked in deionized water and alkaline solution $\left(\mathrm{pH}=13\right.$ ) at $60{ }^{\circ} \mathrm{C}$ last up to 180 days. As shown in Figure $1 \mathrm{~b}$, aluminum end-tabs were used in two ends to avoid the premature damage of the specimen during the tensile test. According to ASTM D3039 [41], the monotonic tensile test was conducted using a universal machine (Model WDE-200E, Jinan Gold Testing Machines Inc., Jinan, China) through displacement control with a displacement speed of $2 \mathrm{~mm} / \mathrm{min}$. The tensile stress $\sigma$ could be calculated according to the Equation (2) and the strain was measured using an extensometer with a gauge length (Model Y50/10, Changchun Sanjing Test Instrument Co., Ltd., Changchun, China) of $50 \mathrm{~mm}$ in the test, as shown in 
Figure 2. It should be noted that the acquired tensile stress was nominal tensile stress, which is more convenient to apply in practice engineering. Five specimens of each thickness were tested at specific duration, the average values and standard deviation of tensile strength retention and tensile elastic modulus were respectively calculated.

$$
\sigma=\frac{F}{A}
$$

where $F$ represents the measured tensile force. A represents the nominal cross-sectional area of the specimens.

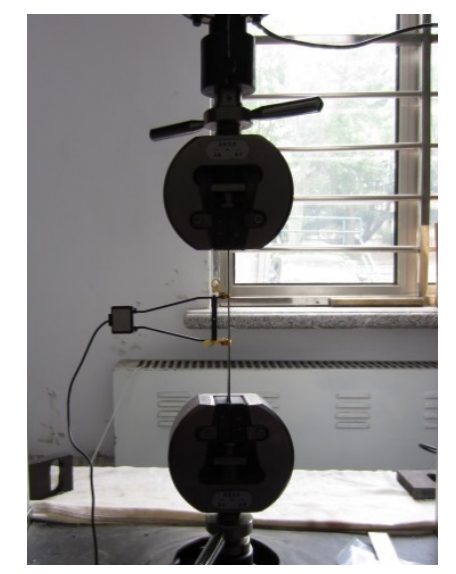

Figure 2. Tensile test of BFRP laminates.

\subsection{Scanning Electron Microscopy}

Fractured surfaces of tensile failure specimens were observed using scanning electron microscopy (SEM) (Model Nova NanoSEM450, FEI Inc., Oregon, USA) at an accelerated voltage of $15 \mathrm{kV}$. All the observed specimens were sprayed with gold powder to increase their conductivity for easy observation [22,29].

\section{Test Results}

\subsection{Water Absorption}

Figure 3 shows the average values of the water absorption of BFRP laminates soaked in $60^{\circ} \mathrm{C}$ deionized water and alkaline solution. It can be seen that the values of error bars were generally small, indicating that the dispersions of results were acceptable. It is noted that the water absorption of all specimens increased first before reaching their peak water absorption and then decreased as the ageing time increased. When soaked in deionized water and alkaline solution at $60{ }^{\circ} \mathrm{C}$, the peak water absorption of the specimens $B_{1}, B_{2}$ and $B_{4}$ were $1.31 \%, 1.16 \%, 0.96 \%$ and $1.60 \%, 1.52 \%, 1.50 \%$, respectively. After a 180-day immersion, the water absorption of specimens $B_{1}, B_{2}$ and $B_{4}$ decreased to $0.18 \%,-0.43 \%,-1.16 \%$ for deionized water immersion and to $-0.27 \%,-0.73 \%$ and $-2.15 \%$ for alkaline solution immersion, respectively. Generally, the water absorption of FRP composites increased gradually in the initial ageing duration. After that, the water absorption reached the dynamic moisture equilibrium or kept increasing. However, the water absorption curve of this paper, as shown in Figure 3 , was quite different from the general cases reported in the existing literature [42,43]. The decline in water absorption after reaching its peak water absorption was probably caused by the serious degradation of the resin matrix in hygrothermal environment. The water absorption changes of BFFRP laminates were mainly affected by water immersion and hydrolysis of epoxy resin. When the mass gain of epoxy matrix from water immersion was less than the mass loss of epoxy resin due to the hydrolysis, the water absorption of BFRP laminates began to decline. As the degree of hydrolysis of epoxy resin increased, the water absorption of aged BFRP laminates were lower than that without ageing. This 
abnormal water absorption behavior (i.e., the decline in water absorption after reaching its peak water absorption) was also reported in the other literature [44-46].
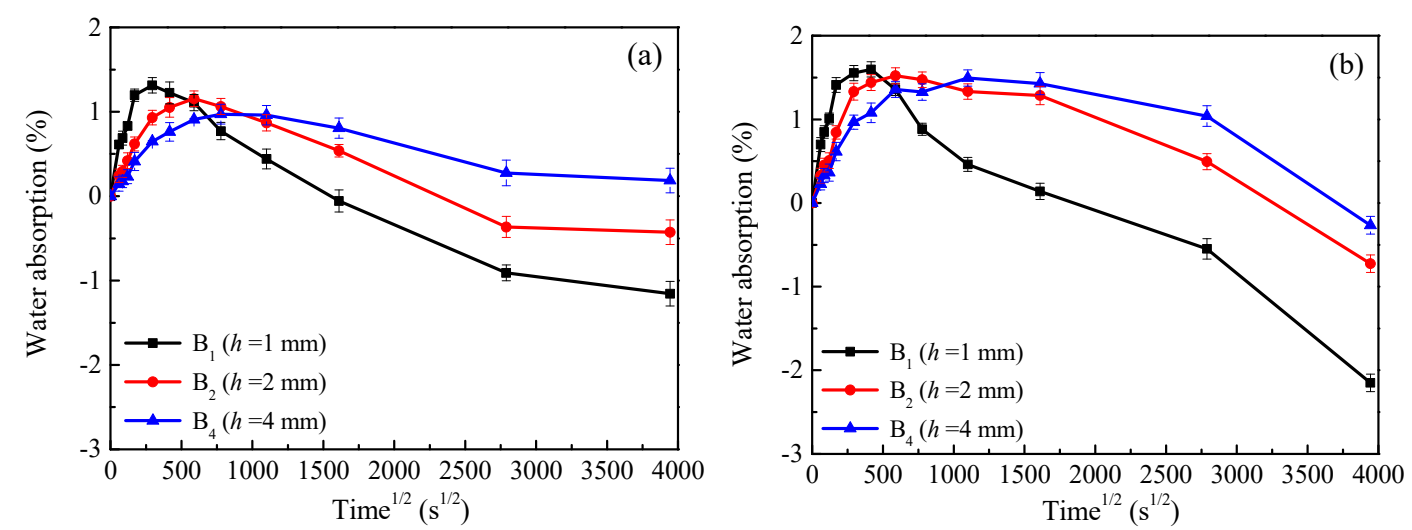

Figure 3. Water absorption of BFRP specimens soaked in $60{ }^{\circ} \mathrm{C}$ (a) deionized water and (b) alkaline solution.

Figure 4 shows the degradation mechanism of epoxy resin soaked in deionized water or alkaline solution. It should be noted that the proportion of each part of the schematic is not drawn strictly according to the actual size, but just to better explain what needs to be expressed. The complete epoxy molecular chains of epoxy resin are presented in Figure 4a. When the BFRP laminates were immersed in high-temperature (i.e., $60^{\circ} \mathrm{C}$ ) deionized water or alkaline solution for a period of immersion time, lots of water molecules and/or $\mathrm{OH}^{-}$accelerate the erosion to epoxy resin, leading to the hydrolysis reaction of epoxy resin. The hydrolysis reaction is that the ether bonds $(\mathrm{C}-\mathrm{O})$ of epoxy molecular chains are broken as shown in Figure 4a. At this time, the epoxy molecular chains were broken down and formed some short molecular chains, dissolved in the solution finally. Macroscopically, the hydrolysis process of epoxy resin could be characterized by the appearance of some voids and micro-cracks after the water molecules and/or $\mathrm{OH}^{-}$deteriorated to epoxy resin as shown in Figure $4 \mathrm{~b}$. In order to verify the degradation mechanism, SEM observations were also conducted. The representative SEM images were selected from lots of SEM images; similar phenomena were observed in different regions of different samples. Figure 5a shows the surface of unaged specimen that was intact without ageing defects. Figure $5 b, c$ represent the aged specimen in $60{ }^{\circ} \mathrm{C}$ deionized water and alkaline solution for 180 days, respectively. It can be seen that some obvious voids and micro-cracks appeared on the surface of the aged specimens, which supported the degradation mechanism of epoxy resin shown in Figure 4. Moreover, it can also be seen that, compared with the micro-cracks soaked in deionized water in Figure $5 b$, the extended micro-cracks appeared in Figure $5 c$ due to the erosion of $\mathrm{OH}^{-}$in alkaline solution. A more severe hydrolysis reaction occurred on the specimens soaked in alkaline solution compared with the specimens soaked in deionized water. Therefore, the change range of water absorption was greater for alkaline solution immersion. In addition, it should be noted that it is significant to quantify the micro-cracks for a better understanding the hygrothermal ageing on epoxy resin. The related work will be included in a future study. 
<smiles>[R]COC(C[R])Cc1ccc(Oc2ccc(OCC(O)C(C)Oc3ccc(C(C)(C)c4ccc(OC)cc4)cc3)cc2)cc1</smiles>

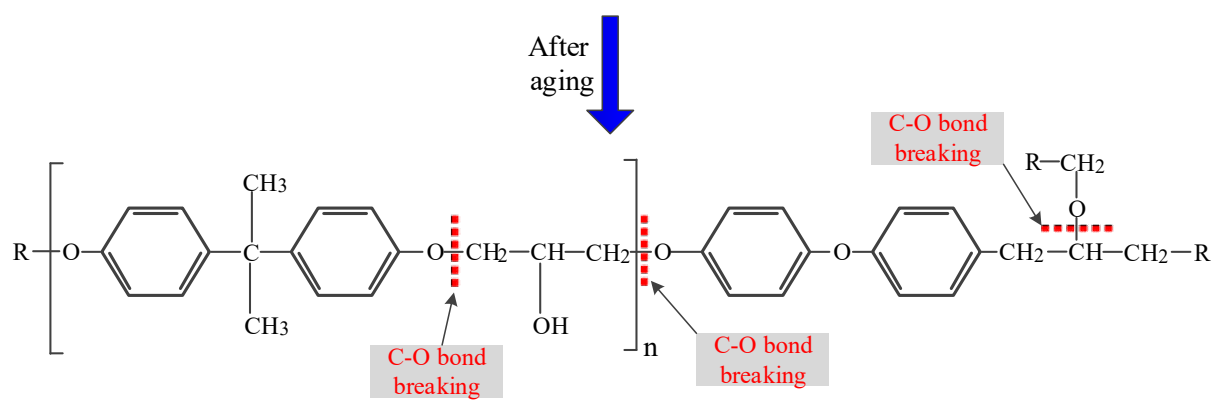

(a)
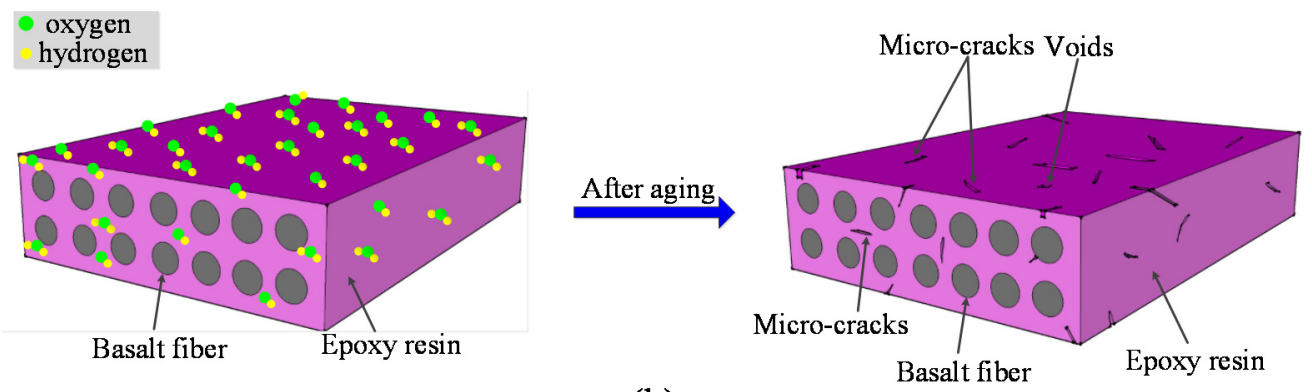

(b)

Figure 4. Degradation mechanism of epoxy resin in $60{ }^{\circ} \mathrm{C}$ deionized water or alkaline solution. (a) breaking down of epoxy molecular chains $(\mathbf{b})$ ageing damage of epoxy resin in macroscopy.
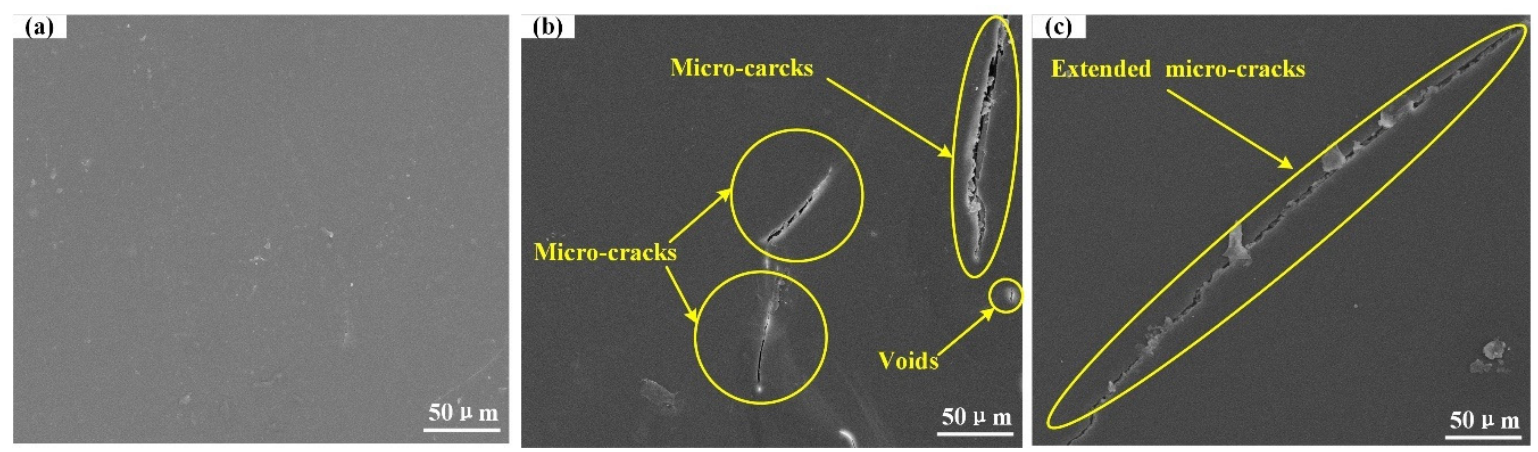

Figure 5. SEM images of (a) unaged specimen surface; Aged surfaces of the specimens soaked (b) deionized water and (c) alkaline solution at $60^{\circ} \mathrm{C}$ after 180 ageing days.

\subsection{Tensile Properties}

Table 2 gives the average values with standard deviations of the tensile strength $(f)$ and elastic modulus $(E)$ of the specimens at specific ageing time. The average values of the tensile strength retention and elastic modulus retention are plotted against ageing time in Figures 6 and 7, respectively. It can be seen that the variation of error values was small overall, which can be considered that the results of the tensile test were accurate and reasonable. It can be found from Figure 6, in the first 14 days, the tensile strength decreased rapidly by $20 \%-40 \%$. Afterward, the tensile strength showed a slower decline with the increase of ageing time. After an ageing of 180 days, the tensile strength retention of specimens $\mathrm{B}_{1}, \mathrm{~B}_{2}$, and $\mathrm{B}_{4}$ in deionized water and alkaline solution were $34.0 \%, 37.7 \%$, $40.6 \%$ and $20.1 \%, 26.3 \%, 33.1 \%$, respectively. It can be seen that the thicker specimens had higher 
tensile strength retention than the thinner specimens. Figure 7 shows elastic modulus retention in deionized water and alkaline solution. The change trends of elastic modulus retention were similar to those of tensile strength retention. However, the degradation rate of elastic modulus is far less than that of tensile strength. After the ageing of 180 days, the maximum decrease of elastic modulus retention of all specimens was around $5 \%-20 \%$.

Table 2. Degradation of tensile strength $(f)$ and elastic modulus $(E)$ of BFRP laminates with different thicknesses.

\begin{tabular}{cccccc}
\hline \multirow{2}{*}{$\begin{array}{c}\text { Specimen } \\
\text { Thickness }\end{array}$} & $\begin{array}{c}\text { Ageing } \\
\text { Days }\end{array}$ & \multicolumn{2}{c}{ Deionized Water } & \multicolumn{2}{c}{ Alkaline Solution } \\
\cline { 2 - 5 } & & $f$ & $\boldsymbol{E}$ & $f$ \\
$\mathbf{( M P a )}$ & $\mathbf{( G P a )}$ & $\mathbf{( M P a )}$ & $\begin{array}{c}\boldsymbol{E} \\
\mathbf{( G P a )}\end{array}$ \\
\hline & 0 & $1763 \pm 41$ & $81.8 \pm 0.8$ & $1763 \pm 41$ & $81.8 \pm 0.8$ \\
$1 \mathrm{~mm}$ & 7 & $1345 \pm 34$ & $79.1 \pm 0.7$ & $1227 \pm 34$ & $78.6 \pm 0.7$ \\
$\left(\mathrm{~B}_{1}\right)$ & 14 & $1059 \pm 28$ & $75.3 \pm 0.7$ & $1056 \pm 29$ & $78.0 \pm 0.6$ \\
& 30 & $1042 \pm 28$ & $74.6 \pm 0.7$ & $1012 \pm 27$ & $79.7 \pm 0.6$ \\
& 90 & $851 \pm 22$ & $73.5 \pm 0.7$ & $599 \pm 16$ & $78.2 \pm 0.6$ \\
& 180 & $600 \pm 14$ & $70.3 \pm 0.6$ & $354 \pm 10$ & $65.5 \pm 0.7$ \\
\hline & 0 & $1830 \pm 44$ & $85.1 \pm 0.9$ & $1830 \pm 44$ & $85.1 \pm 0.8$ \\
$\left(\mathrm{~B}_{2}\right)$ & 7 & $1390 \pm 38$ & $82.5 \pm 0.7$ & $1252 \pm 34$ & $81.5 \pm 0.9$ \\
& 14 & $1148 \pm 31$ & $80.2 \pm 0.7$ & $1159 \pm 30$ & $79.3 \pm 0.7$ \\
& 30 & $1121 \pm 26$ & $79.9 \pm 0.6$ & $1057 \pm 28$ & $77.0 \pm 0.6$ \\
& 90 & $885 \pm 22$ & $77.3 \pm 0.6$ & $759 \pm 21$ & $75.8 \pm 0.5$ \\
& 180 & $689 \pm 17$ & $75.7 \pm 0.7$ & $481 \pm 13$ & $71.7 \pm 0.6$ \\
\hline & 0 & $1782 \pm 42$ & $83.5 \pm 0.8$ & $1782 \pm 42$ & $83.5 \pm 0.8$ \\
$\left(\mathrm{~B}_{4}\right)$ & 7 & $1420 \pm 39$ & $80.4 \pm 0.7$ & $1354 \pm 38$ & $82.9 \pm 0.6$ \\
& 14 & $1279 \pm 34$ & $78.5 \pm 0.7$ & $1230 \pm 34$ & $79.5 \pm 0.6$ \\
& 30 & $1174 \pm 32$ & $78.2 \pm 0.6$ & $1099 \pm 30$ & $79.1 \pm 0.6$ \\
& 90 & $993 \pm 26$ & $78.8 \pm 0.6$ & $946 \pm 25.4$ & $77.5 \pm 0.7$ \\
& 180 & $723 \pm 16.2$ & $77.5 \pm 0.7$ & $590 \pm 15.2$ & $75.6 \pm 0.6$ \\
\hline
\end{tabular}
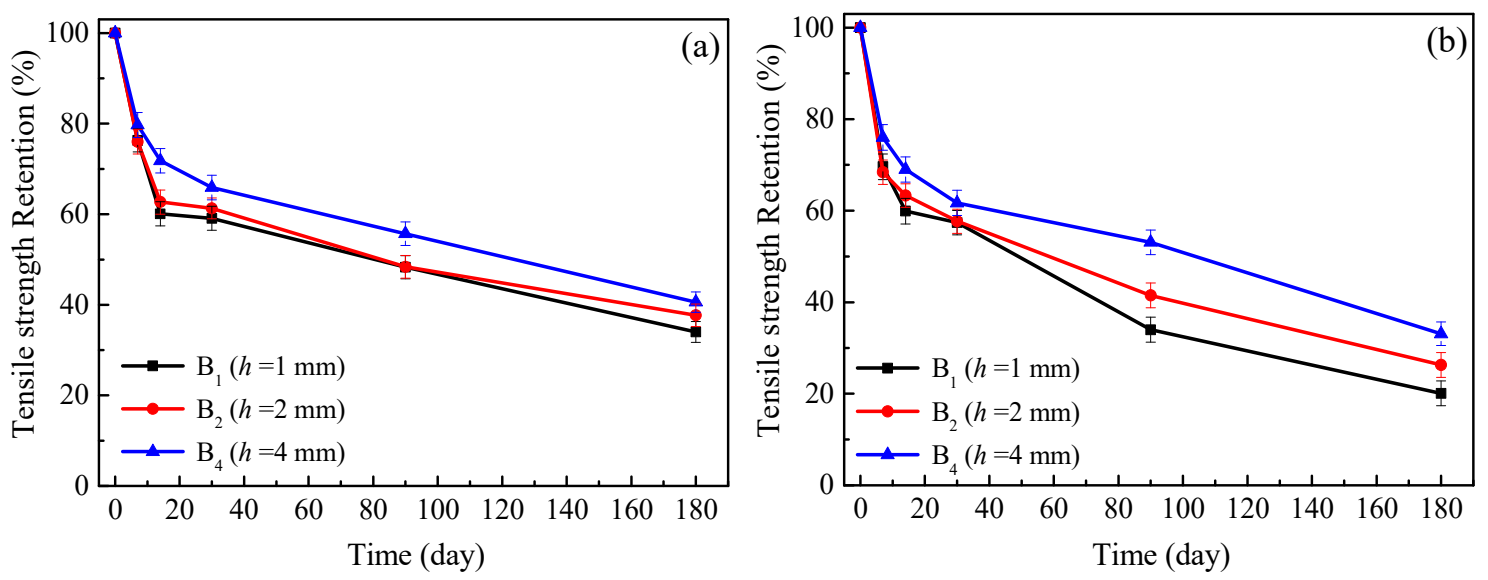

Figure 6. Variations of tensile strength retention of BFRP laminates vs. ageing time soaked in (a) deionized water and (b) alkaline solution at $60^{\circ} \mathrm{C}$. 

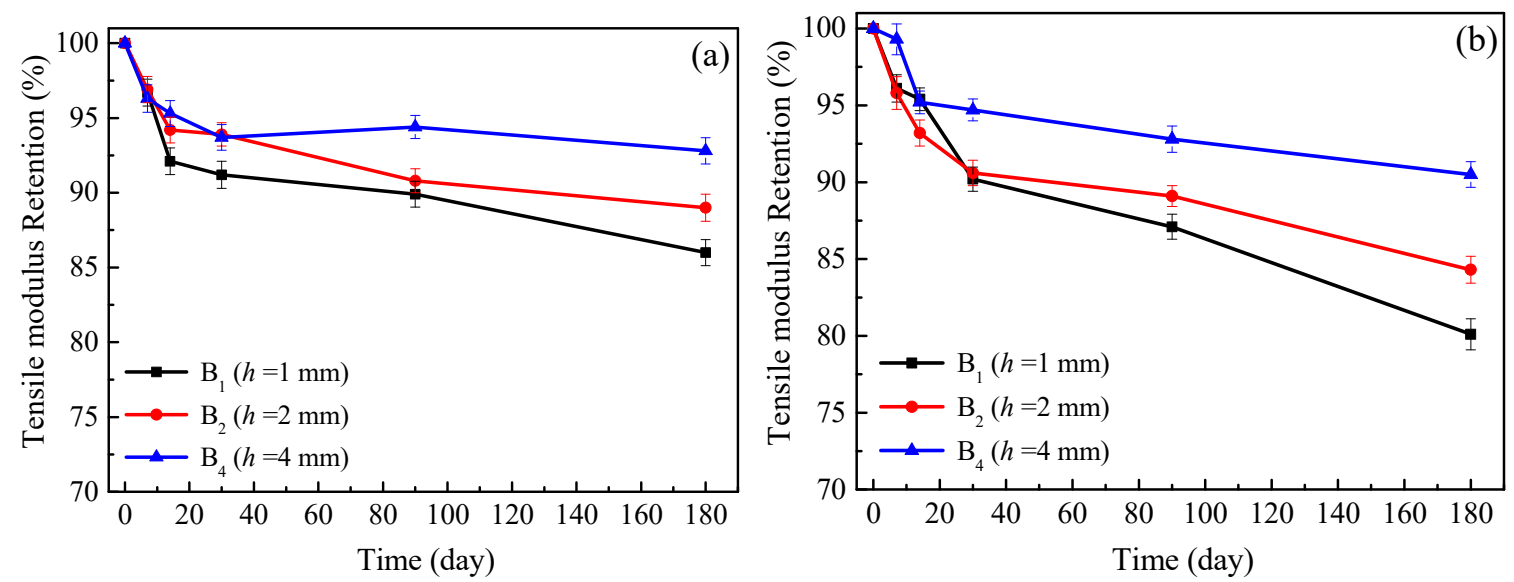

Figure 7. Variations of elastic modulus retention of BFRP laminates vs. ageing time soaked in (a) deionized water and (b) alkaline solution at $60{ }^{\circ} \mathrm{C}$.

According to the SEM images of tensile failure surfaces of unaged and aged specimens shown in Figure 8, the degradation of tensile properties of BFRP laminates mainly comes from two parts. One is the degradation of epoxy resin and the corresponding interfacial debonding between the basalt fiber and the epoxy resin. Figure 8a exhibits the tensile failure surface of unaged specimen, where the basalt fiber was perfectly bonded to epoxy resin. It means that the basalt fiber and the epoxy resin play a synergistic role in the process of stress transmission during tension for unaged specimens. At the beginning of ageing, as shown in Figure 8b, the interfacial bond between basalt fiber and epoxy resin was gradually weakened due to the hydrolysis reaction of epoxy resin, leading to partial interfacial debonding. As the increase of ageing time, the hydrolysis of epoxy resin would be more severe as shown in Figure 8c (180 days). The other is the ageing of basalt fiber. SEM images of basalt fiber before and after ageing were shown in Figure $8 \mathrm{~d}-\mathrm{f}$, respectively. It can be seen that the basalt fiber was also deteriorated due to the chemical reactions. Basalt fibers are composed of $\mathrm{SiO}_{2}$ with tetrahedral network structure, in which silicon and oxygen account for $27 \%$ and $44 \%$ of the total elements, respectively [47]. When basalt fiber was exposed to the solution, $\mathrm{H}_{2} \mathrm{O}$ and $\mathrm{OH}^{-}$played a significant role in the deterioration of basalt fiber. The chemical reaction formula of basalt fiber is shown as Equation (3). $\mathrm{OH}^{-}$attacks the molecular chains of $\mathrm{SiO}_{2}$, causing a part of $\mathrm{SiO}_{2}$ chains to relax. After that, the produced $\mathrm{SiO}^{-}$further react with $\mathrm{H}_{2} \mathrm{O}$ to produce $\mathrm{OH}^{-}$to intensify the reaction of Equation (3) [47,48], as follows in Equation (4). Besides, $\mathrm{SiOH}$ produced from $\mathrm{SiO}^{-}$is a kind of white colloid, which can transfer $\mathrm{H}_{2} \mathrm{O}$ and $\mathrm{OH}^{-}$to approach $\mathrm{SiO}_{2}$ bone chains, and further deteriorate basalt fiber. Since the reaction rate of $\mathrm{SiO}_{2}$ bone chains is relatively slow, the degradation of tensile strength and elastic modulus decreased slowly in the late stage, consistent with the experimental results (shown in Figures 6 and 7).

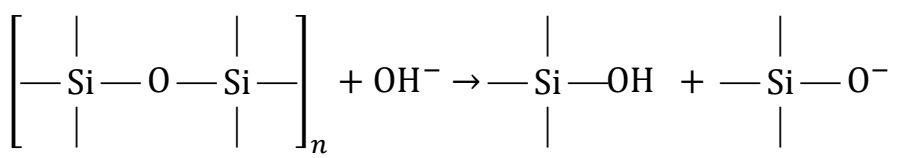

$$
\left[\underset{\mid}{\mid} \mathrm{Si}-\mathrm{O}^{-}\right]_{n}+\mathrm{H}_{2} \mathrm{O} \rightarrow-\underset{\mid}{\mid} \mathrm{Si}-\mathrm{OH}+\mathrm{OH}^{-}
$$



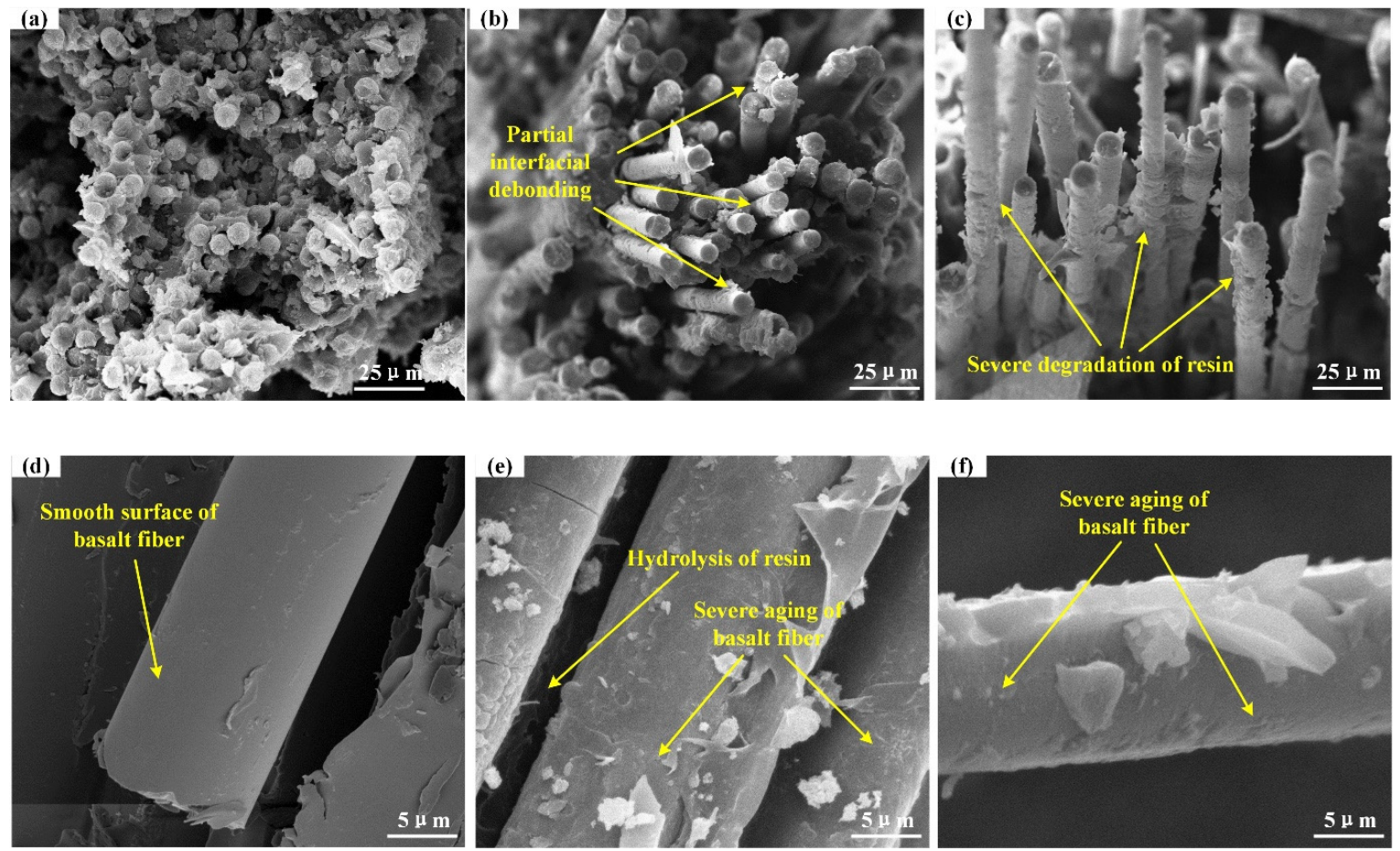

Figure 8. SEM images of tensile failure surfaces: (a) unaged specimen; aged specimen soaked in $60{ }^{\circ} \mathrm{C}$ alkaline solution last (b) 14 days and (c) 180 days; (d) unaged basalt fiber; aged basalt fiber soaked in $60{ }^{\circ} \mathrm{C}(\mathbf{e})$ deionized water and (f) alkaline solution last 180 days.

\section{Discussions}

\subsection{Influence of Thickness on Water Absorption}

The measured water absorption was analyzed against specimen thickness at specific ageing days (Figures 9 and 10). Figure 9a,b show that water absorption of the specimens decreased by increasing specimen thickness in the early stage (less than two days) of the immersion in deionized water and alkaline solution, respectively. In other words, the thinner the specimen thickness, the faster the water absorption saturation was achieved. As shown in Figure $9 \mathrm{c}, \mathrm{d}$, when the ageing time increased to four and seven days, the water absorption rose and then declined as the increasing specimen thickness. This is because in this ageing stage the change in the weight of specimen $B_{1}$ began to be dominated by the hydrolysis of the epoxy resin (reducing the weight of the specimen) rather than water absorption (increasing the weight of the specimen). While the changes in the weight of specimen $B_{2}$ and $B_{3}$ were still dominated by water absorption. At this time, the mass gain of specimen $B_{1}$ from water absorption was less than the mass loss of epoxy resin due to the hydrolysis, leading to a decrease of measured water absorption of specimen $\mathrm{B}_{1}$. As shown in Figure 10, the water absorption trend in late stage of the immersion (14-180 days) was opposite to that in early stage, indicating that the mass loss of all specimens due to the hydrolysis of epoxy resin was more than the mass gain of water absorption in this stage. The mass loss of thinner specimen $\left(B_{1}\right)$ was still greater than that of thicker specimens $\left(B_{2}, B_{4}\right)$ in late stage, meaning that a thinner specimen had a greater hydrolysis degree at the given ageing time.

It is noteworthy that the water absorption of BFRP laminates was studied by considering the epoxy resin and the basalt fiber as a whole in this study. It is significant to determine water absorptions of the resin and basalt fiber respectively for a better understanding of the water absorption mechanism. In a future study, the related work (i.e., separately studying the water absorption of the resin and the basalt fiber) will be incorporated in the authors' study target. 

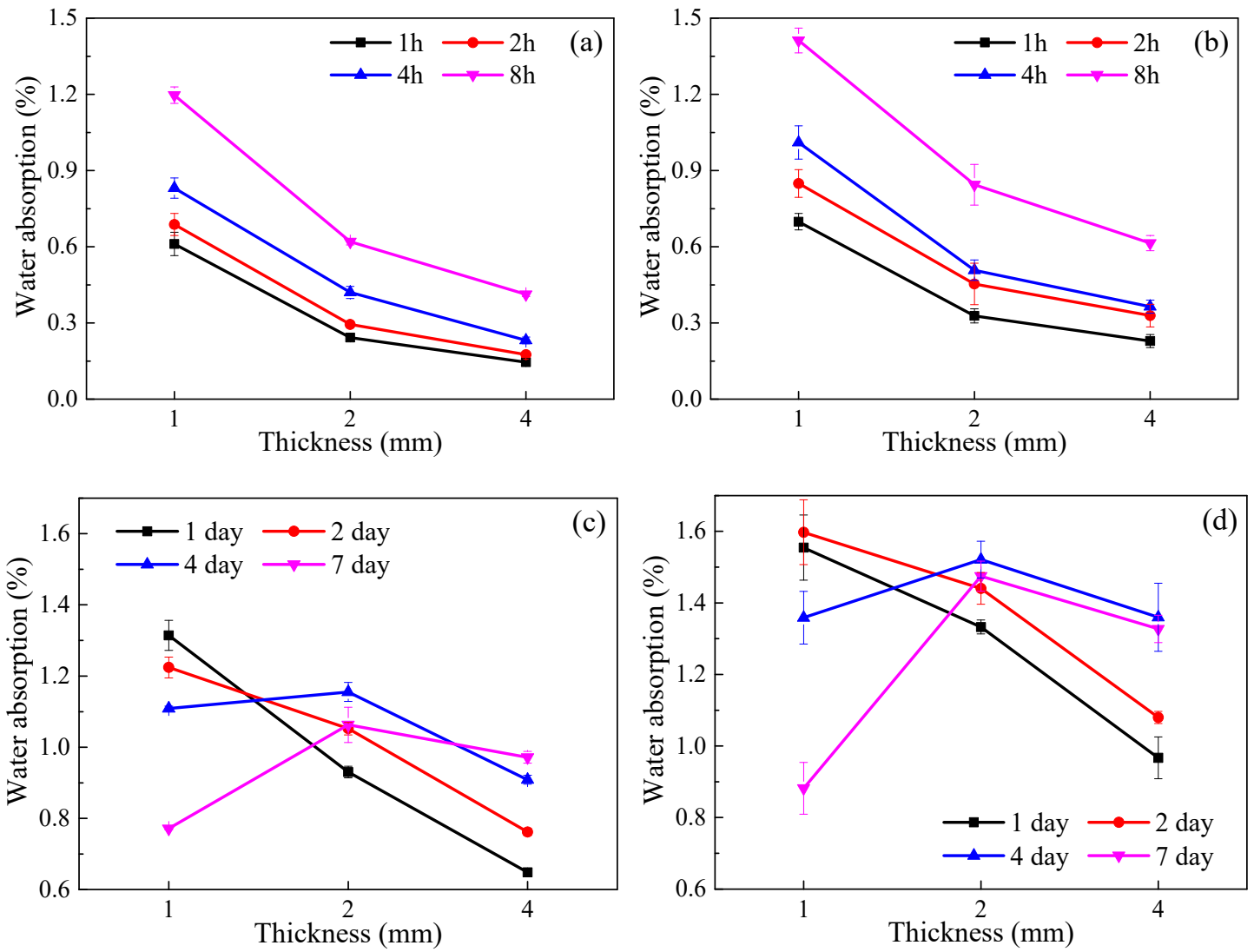

Figure 9. Variation of water absorption vs. specimen thickness soaked in (a,c) deionized water and $(\mathbf{b}, \mathbf{d})$ alkaline solution in early stage.
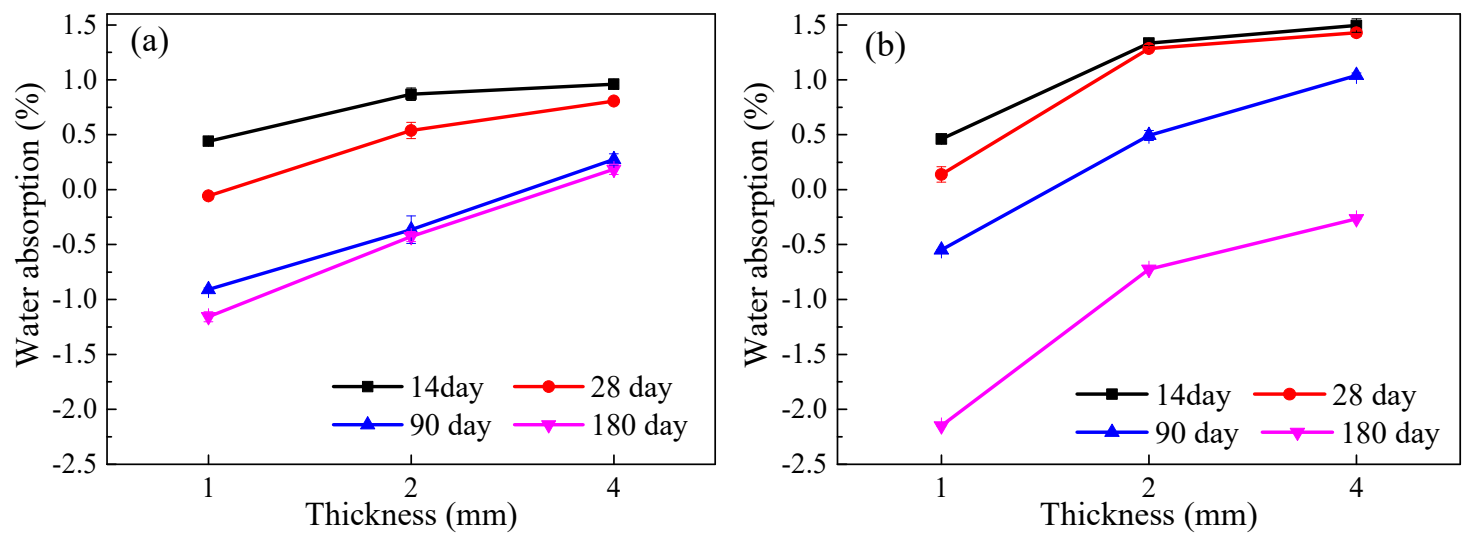

Figure 10. Variation of water absorption vs. specimen thickness soaked in (a) deionized water and (b) alkaline solution in late stage.

\subsection{Influence of Thickness on Tensile Strength}

The tensile strength retention vs. specimen thickness under different ageing durations was plotted in Figure 11. It can be observed that the specimens with thinner thickness had smaller retention than that of specimens with thicker thickness at given ageing time. For example, the tensile strength retention of specimen $B_{1}$ was $5 \%-20 \%$ lower than that of specimen $B_{4}$. Combining the test results of tensile test and water absorption, it can be concluded that at the beginning of ageing (around 30 days), the specimen with a thinner thickness had a faster deterioration rate than that of the specimen with a thicker thickness. After that, the deterioration rate was not sensitive to the thickness, while the ageing degree of the specimen with a thinner thickness was more severe than that of the specimen 
with a thicker thickness during a long period of ageing. Figure 12 shows the ageing of the specimens with different thicknesses through the cross section. It should be noted that the aged areas shown in Figure 12 only represent the aged areas of the specimens at a certain ageing time and the aged areas will gradually increase with the increasing ageing time. Additionally, note that the proportion of each part of the schematic is not drawn strictly according to the actual size, but just to better explain what needs to be expressed. Since the thickness of the specimen is much smaller than its length and width, it can be assumed that the deterioration of the specimen is carried out along the direction of the thickness. The aged area gradually expands to the interior of the specimen with the increase of ageing time. Although the thicknesses of $B_{1}, B_{2}$, and $B_{4}$ are different, the diffusion coefficient of the immersion solution is identical due to the same fabrication materials $[49,50]$. Therefore, the aged areas of $B_{1}, B_{2}$ and $B_{4}$ are the same after a same certain ageing time. It can be seen clearly that the thicker specimen has a larger unaged area, i.e., $S_{1}<S_{2}<S_{4}$. As the ageing time increases, the relationship between the unaged area $S$ of BFRP laminates with different thicknesses was still established, i.e., $\mathrm{S}_{1}<\mathrm{S}_{2}<\mathrm{S}_{4}$. Therefore, a thinner specimen is inferior to a thicker one on long-term hygrothermal properties due to a faster degradation rate.
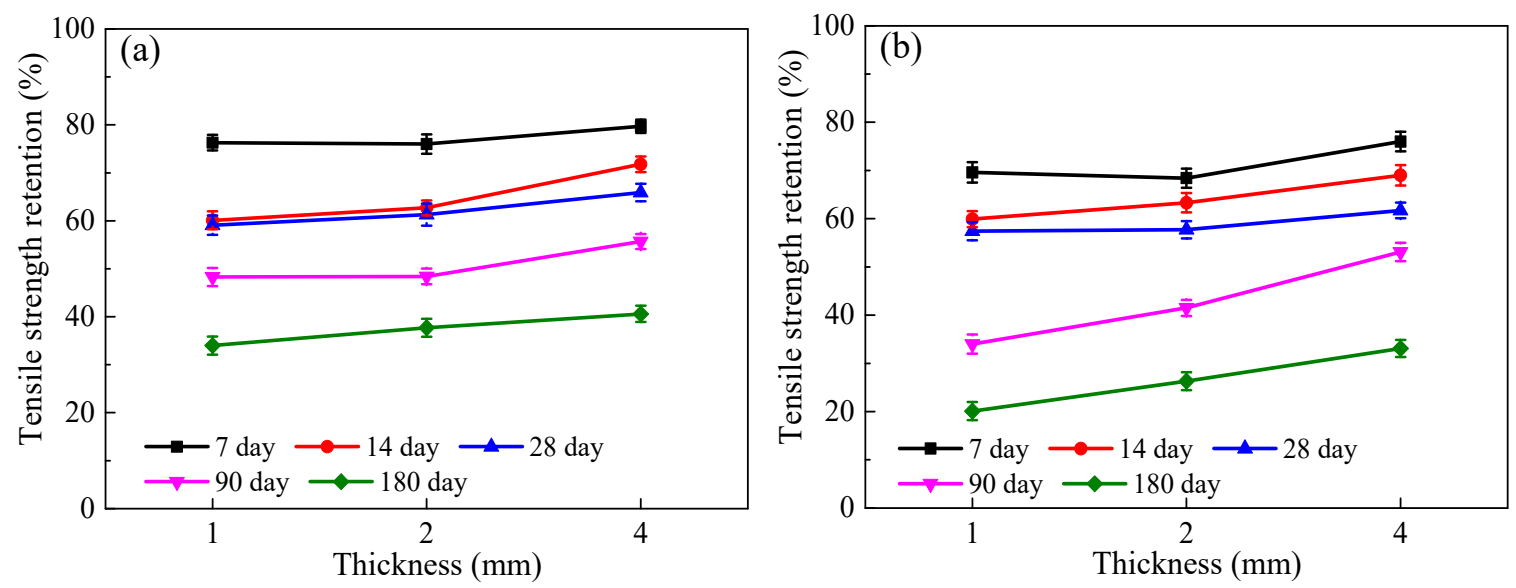

Figure 11. Variation of tensile strength retention vs. specimen thickness soaked in (a) deionized water and (b) alkaline solution at different ageing days.

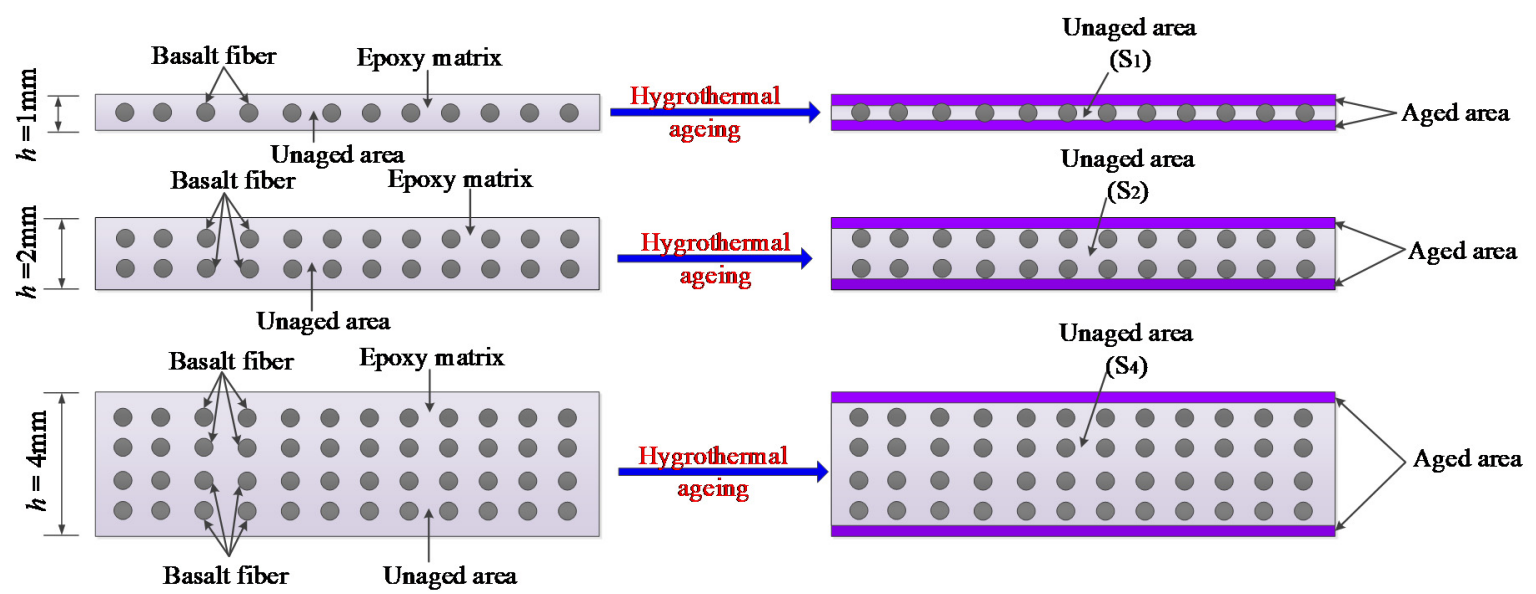

Figure 12. Schematic diagram of the ageing of the specimens with different thicknesses through cross section at a same certain ageing time.

\section{Theoretical Model of Accelerated Factor}

The above experimental results indicated clearly that the water absorption and tensile strength retention of BFRP laminate were dramatically influenced by specimen thickness. As illustrated in 
Figures 3 and 6, it could be observed that the ageing degradation (i.e., the changing trends of water absorption and reduction of tensile strength retention) of BFRP laminates with thinner specimens was more severe than that of thicker specimens when the BFRP laminates were soaked in the solution for a same long time. Therefore, there is a possibility to deduce an accelerated ageing model based on specimen thickness for water absorption and tensile strength retention of BFRP laminates under hygrothermal ageing environment. In this section, a theoretical accelerated ageing model based on specimen thickness was developed and the accelerated factors ( $A F \mathrm{~s}$ ) related to specimen thickness were theoretically deduced.

\subsection{Accelerated Factor of Water Absorption}

Considerable researches show that the water absorption of FRP composites can be described by two models as shown in Figure 13, i.e., the Fick's model and Two-stage model $[39,42,51]$. The Fick's model assumes that the initial phase of water absorption increases linearly with $t^{1 / 2}$ in the initial phase, and then increases non-linearly until the water absorption reaches a dynamic equilibrium without obvious changes. For the Two-stage model, the water absorption is identical to Fick's model in the initial phase. But the water absorption cannot reach the equilibrium stage due to the water immersion constantly and the degradation of resin matrix. In the current study, the test results of water absorption conform to the Two-stage model.
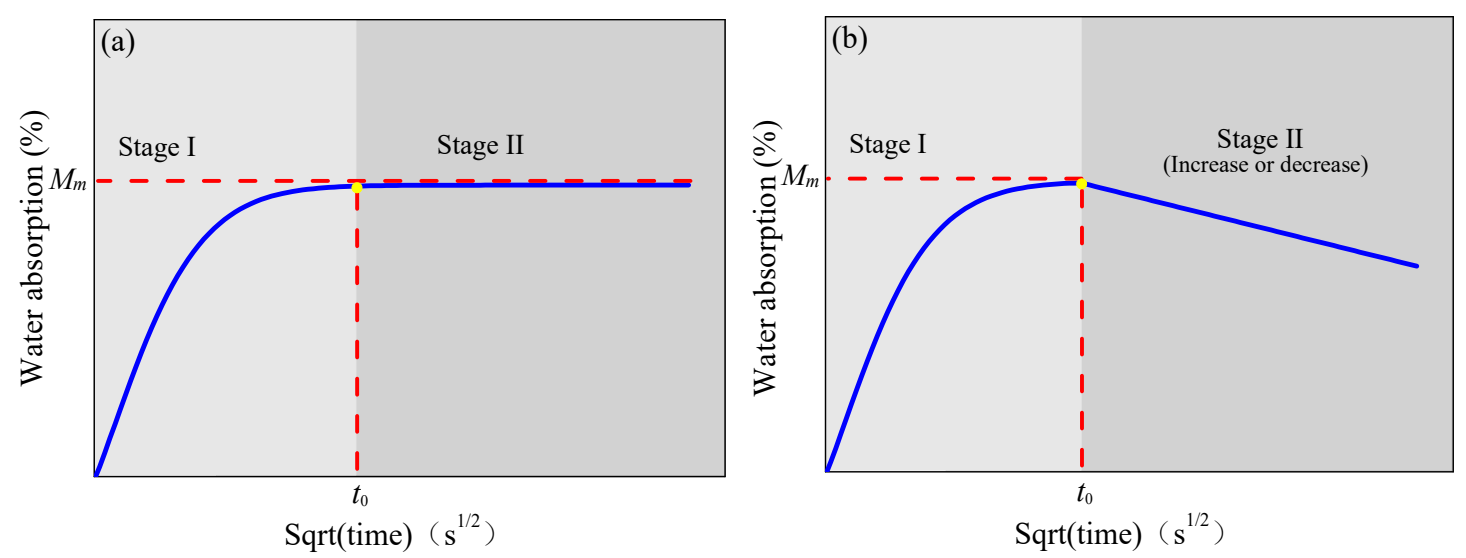

Figure 13. Typical model of water absorption of composites: (a) Fick model; (b) Two-stage model.

According to the ageing mechanism reported in the literature $[49,50]$, the following assumptions can be used to establish the water absorption model. First, the specimens with different thicknesses have the same diffusion rate for the same immersion solution because the diffusion rate is controlled by the concentration gradient of the immersion solution. Second, although the water absorption at the regular time varies with specimen thickness, the ageing mechanism of the composite remains unchanged. Third, the specimens with different thicknesses fabricated by the same material will eventually reach the same water absorption rate under the same immersion solution.

The Fick's and Two-stage models can be used to describe the relationship between specimen thickness and ageing time in stage I (mass gain due to swelling of FRP composites) and stage II (mass loss due to relaxation of FRP composites), respectively. In the two models, the stage I of water absorption is identical. The Fick's model is shown in Equation (5), but it is difficult to find the relationship among different parameters in this expression, which is needed to be simplified as presented in Equation (6) [36,40].

$$
M(t)=M_{\infty}\left\{1-\frac{8}{\pi^{2}} \sum_{j=0}^{\infty} \frac{\exp \left[-(2 j+1)^{2} \pi^{2}\left(\frac{D t}{h^{2}}\right)\right.}{(2 j+1)^{2}}\right\}
$$




$$
M(t)=M_{\infty}\left\{1-\exp \left[-7.3\left(\frac{D t}{h^{2}}\right)^{0.75}\right]\right\}
$$

where $M_{\infty}$ is the effective moisture equilibrium content, $D$ is the diffusion coefficient.

When two specimens with the thicknesses of $h_{1}$ and $h_{2}$ soaked in the same solution reach the same water absorption at ageing time $t_{1}$ and $t_{2}$, respectively. The equilibrium equation, i.e., $M\left(t_{1}\right)=M\left(t_{2}\right)$ can be expressed as Equation (7) according to Fick's model, which can be simplified to Equation (8).

$$
\begin{aligned}
M_{\infty}\left\{1-\exp \left[-7.3\left(\frac{D t_{1}}{h_{1}{ }^{2}}\right)^{0.75}\right]\right\} & =M_{\infty}\left\{1-\exp \left[-7.3\left(\frac{D t_{2}}{h_{2}^{2}}\right)^{0.75}\right]\right\} \\
\exp \left[-7.3\left(\frac{D t_{1}}{h_{1}{ }^{2}}\right)^{0.75}\right] & =\exp \left[-7.3\left(\frac{D t_{2}}{h_{2}^{2}}\right)^{0.75}\right]
\end{aligned}
$$

According to the previous assumptions, the diffusion coefficient $D$ is identical when the specimens are soaked in the same solution, yields

$$
\frac{t_{1}}{t_{2}}=\frac{h_{1}^{2}}{h_{2}^{2}}
$$

Therefore, the $A F$ of water absorption in stage I of Two-stage model can be expressed in

$$
A F=\frac{t_{1}}{t_{2}}=\left(\frac{h_{1}}{h_{2}}\right)^{2}
$$

After the above derivation of $A F$ in Stage I, it can be found that there is a certain relationship between ageing time $t$ and specimen thickness $h$ indeed. To further explore the relationship between water absorption, ageing time $t$ and specimen thickness $h$ in stage II of Two-stage model, the abscissa of water absorption curves can be changed from $t^{1 / 2}$ to $t / h^{2}$, as shown in Figure 14. According to the literature [48], the changing the abscissa (from $t^{1 / 2}$ to $t / h^{2}$ ) does not change the trends of water absorption in Stage I and Stage II. The water absorption curve of Two-stage model in Stage II was regarded as declining linearly that is determined by the slope of the descending section, $\tan \alpha$, which is only related to the materials of FRP composite and conditional environment [42,51]. It is known clearly that the tan $\alpha$ of water absorption curves in Stage II is identical for the specimens $B_{1} B_{2}$ and $B_{4}$ due to the same materials of BFRP laminates and conditional environment. Therefore, in the whole Stage II of the Two-stage model, the relationship between water absorption $M(t)$ at any given time and the maximum water absorption $M_{m}$ can be expressed as

$$
M(t)=M_{m}-\frac{t-t_{0}}{h^{2}} \cdot \tan \alpha
$$

When the specimens with two thicknesses $h_{1}$ and $h_{2}$ reach the same water absorption at $t_{1}$ and $t_{2}$, respectively, the equilibrium equation can be expressed as Equation (12)

$$
M_{m}-\frac{t_{1}-t_{01}}{h_{1}^{2}} \cdot \tan \alpha=M_{m}-\frac{t_{2}-t_{02}}{h_{2}^{2}} \cdot \tan \alpha
$$

Equation (12) can be simplified as

$$
\frac{t_{1}-t_{01}}{h_{1}^{2}}=\frac{t_{2}-t_{02}}{h_{2}^{2}}
$$


It has been known by the derivation of Stage I in the two water absorption models that the Equation (10) is applicable when the value of water absorption increases to $M_{m}$, i.e.,

$$
\frac{t_{01}}{h_{1}^{2}}=\frac{t_{02}}{h_{2}^{2}}
$$

Thus, the $A F$ of stage II in Two-stage model can be expressed by Equation (10).

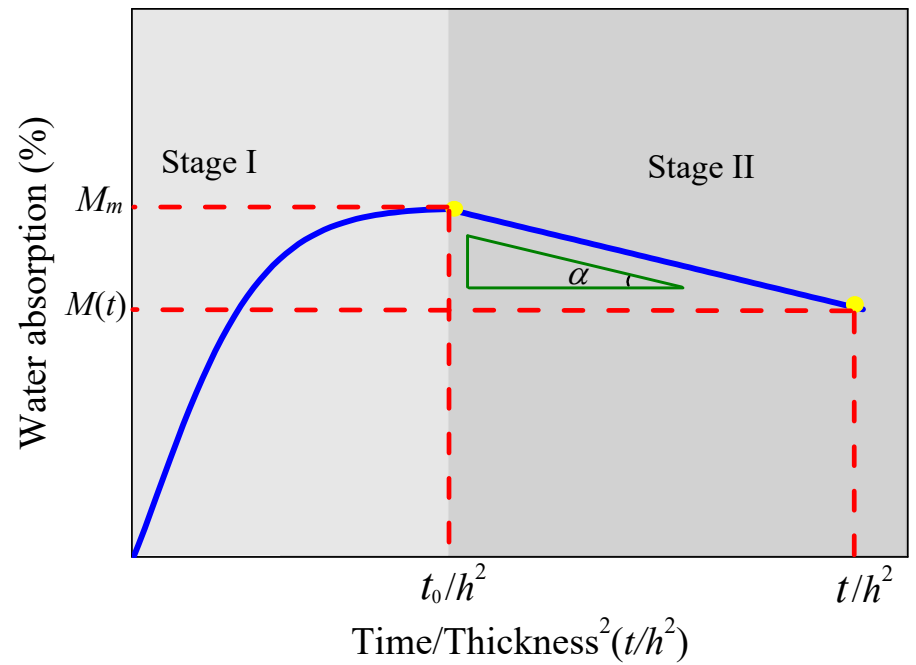

Figure 14. Two-stage model with the abscissa changed to $t / h^{2}$.

Therefore, the accelerated factor based on specimen thickness for water absorption is deduced theoretically, which can be applied in Fick's model and Two-stage model.

\subsection{Accelerated Factor of Tensile Strength Retention}

When the tensile specimens are soaked in the solution, the tensile strength decreases due to the gradual increase of the ageing area. The ageing condition of tensile specimens can be represented by the change of the cross section as shown in Figure 15, which is assumed that the specimen is uniformly aged along the thickness direction on the upper and lower sides. Thus, the actual tensile strength $\sigma$ can be expressed by Equation (15).

$$
\sigma=\frac{\sigma_{u} \cdot A_{u}+\sigma_{a} \cdot A_{a}}{b h}=\frac{\sigma_{u} \cdot b \cdot(h-x)+\sigma_{a} \cdot b \cdot x}{b h}=\sigma_{u}-\left(\sigma_{u}-\sigma_{a}\right) \frac{\mathrm{x}}{h}
$$

where $\sigma_{u}$ and $\sigma_{a}$ are the initial (unaged) and residual (aged) tensile strength of the specimen, respectively. $A_{u}$ and $A_{a}$ are the unaged area and aged area of the specimen, respectively. $b$ and $h$ are the width and thickness of the specimen, respectively. $x$ is the total ageing depth along the thickness of the laminates.

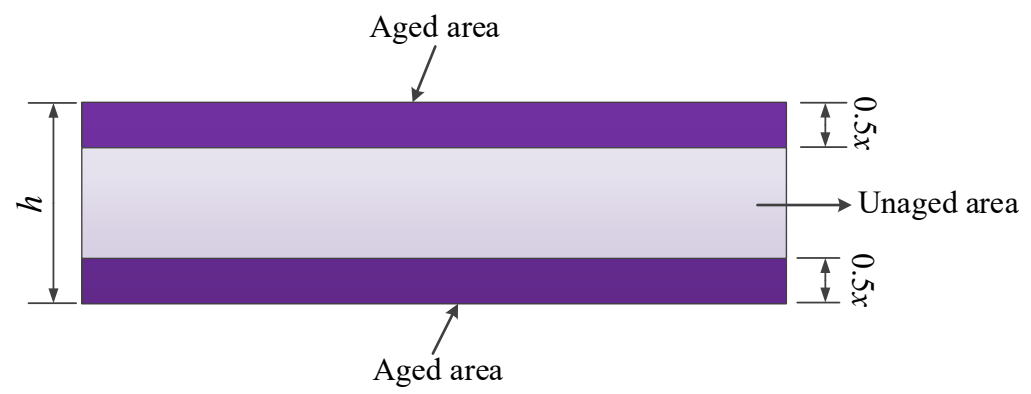

Figure 15. Schematic diagram of ageing along cross section for BFRP laminates. 
It has been reported by study $[49,52,53]$ that the total ageing depth $x$ of the laminates is proportional to the square root of the immersion time $t$, which is as follows regarded as a function of

$$
x=\alpha \sqrt{t} \quad(x<h)
$$

where $\alpha$ is a constant of the FRP composite that is irrelevant to specimen thickness $h$.

Then Equation (15) can be transformed as follows

$$
\sigma=\sigma_{u}-\left(\sigma_{u}-\sigma_{a}\right) \frac{\alpha \sqrt{t}}{h}
$$

According to the literature [50,54], for the given resin matrix, fiber, fabrication and immersion condition, the specimens with different thicknesses will decrease to the same strength when the ageing time is long enough. As a result, the equilibrium equation can be expressed as Equation (18) when the tensile strengths of the specimens when two thicknesses, $h_{1}$ and $h_{2}$, decrease to the same value at ageing time $t_{1}$ and $t_{2}$, respectively.

$$
\sigma_{1}=\sigma_{u}-\left(\sigma_{u}-\sigma_{a}\right) \frac{\alpha \sqrt{t_{1}}}{h_{1}}=\sigma_{2}=\sigma_{u}-\left(\sigma_{u}-\sigma_{a}\right) \frac{\alpha \sqrt{t_{2}}}{h_{2}}
$$

Thus, the $A F$ of tensile strength retention of BFRP laminates can also be written as Equation (10).

From the previous theoretical derivation, for BFRP laminates with two thicknesses, when the water absorption or tensile strength retention of the BFRP laminates with two different thicknesses reaches the same value, the ratio of the ageing time of the BFRP laminates with the two thicknesses is proportional to the square of the ratio of the corresponding two thicknesses. The square of the ratio of the two thicknesses is considered as accelerated factor $(A F)$. As a result, it is feasible to accelerate ageing by reducing the specimen thickness. For example, if the water absorptions or tensile strength retentions of two BFRP laminates with different thicknesses reach a certain same value, the predicted ageing time of thicker specimen $\left(t_{1}\right)$ can be calculated/accelerated by multiplying the real ageing time of thinner specimen $\left(t_{2}\right)$ by the corresponding accelerated factor, $A F=\left(h_{1} / h_{2}\right)^{2}$, based on the two thicknesses of the thicker specimen $\left(h_{1}\right)$ and thinner specimen $\left(h_{2}\right)$.

\subsection{Model Validation and Discussions}

In this study, the ageing accelerated method was taking the BFRP specimen with the thickness $h=4 \mathrm{~mm}$ as the standard specimen. The AFs of BFRP specimens with $h=1 \mathrm{~mm}, h=2 \mathrm{~mm}$, and $h=4 \mathrm{~mm}$ are calculated by Equation (10) and the results are shown in Table 3. The obtaining of accelerated ageing days is transformed by multiplying the actual ageing days of the thicker specimen by the corresponding AF based on the two thicknesses of the thicker specimen and the standard specimen. According to the existing test results, the accelerated time is up to eight years on the water absorption trend and tensile strength retention of BFRP specimen with $h=4 \mathrm{~mm}$. It should be noted that the transformed results of the specimens with 1 and $2 \mathrm{~mm}$ represent the predicted results of the standard specimen $h=4 \mathrm{~mm}$. Figure 16 shows the long-term prediction of water absorption of BFRP specimens with $h=4 \mathrm{~mm}$ according to the transformed results of 1 and $2 \mathrm{~mm}$ specimens in deionized water and alkaline solution. The predicted curves were fitted by using Matlab (2018a Version, MathWorks, Inc., Massachusetts, USA, 2018). It can be seen from Figure 16 that the predicted curves are fitted well with a Two-stage model in whole. It reveals that the predicted law of water absorption in deionized water was better with Two-stage model than that in alkaline solution. Figure 17 shows the long-term prediction of tensile strength retention of BFRP specimens with $h=4 \mathrm{~mm}$ according to the transformed results of 1 and $2 \mathrm{~mm}$ specimens in deionized water and alkaline solution, which is also fitted well with Phani-Bose's model [55] in whole. 
Table 3. The accelerated factor $A F$ of BFRP laminates with different thicknesses.

\begin{tabular}{lccc}
\hline & \multicolumn{3}{c}{ Specimen Thickness } \\
\cline { 2 - 4 } & $\mathbf{1 ~} \mathbf{~ m m}$ & $\mathbf{2} \mathbf{~ m m}$ & $\mathbf{4} \mathbf{~ m m}$ \\
\hline Accelerated factor $(A F)$ & 16 & 4 & 1 \\
\hline
\end{tabular}
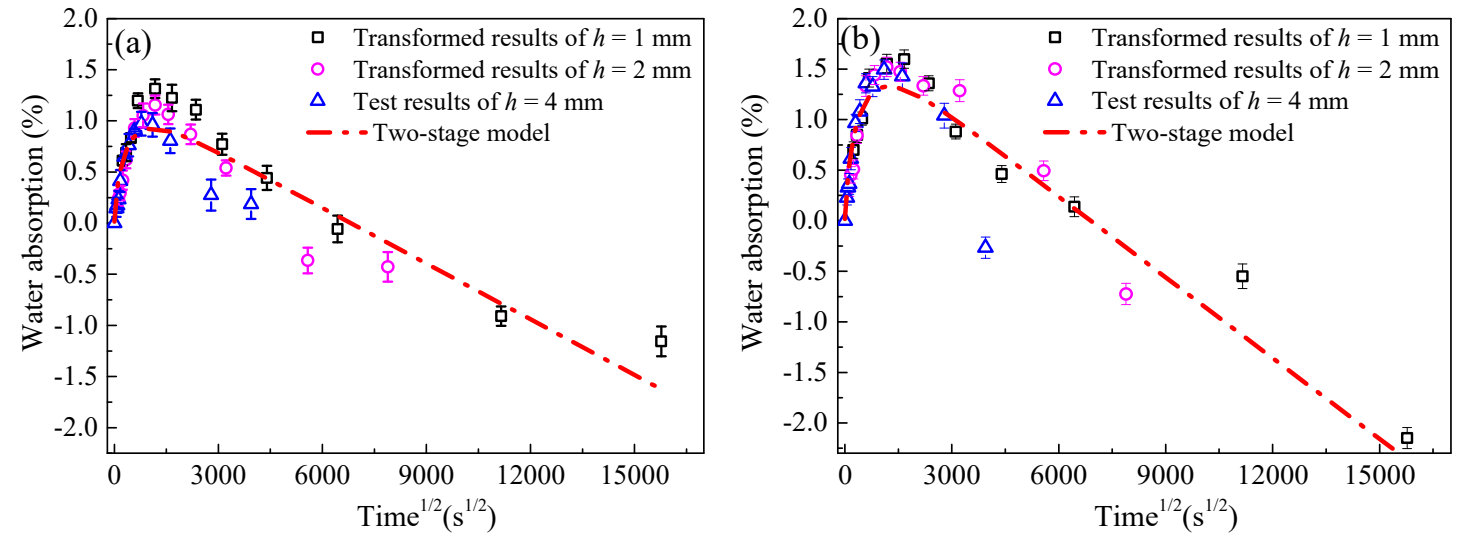

Figure 16. Accelerated ageing results of water absorption based on specimen thickness in (a) deionized water and (b) alkaline solution.
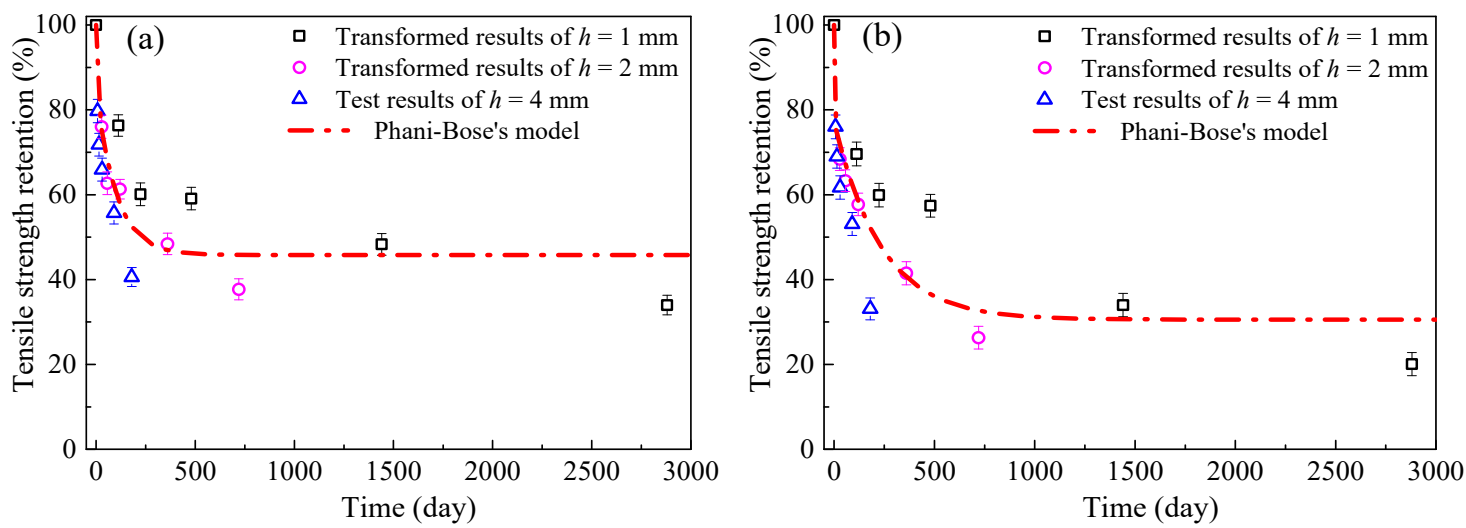

Figure 17. Accelerated ageing results of tensile strength retention based on specimen thickness:

(a) deionized water and (b) alkaline solution.

Compared with the traditional temperature-dependent accelerated ageing method, there are two main advantages of the proposed new specimen thickness-dependent accelerated ageing method in this study. First, the proposed thickness-dependent accelerated ageing method is easy to apply because this method does not need the activation energy, which must be required in the temperature-dependent method. In order to obtain the activation energy in the temperature-dependent method, at least three different temperature environment tests must be conducted [56], which increases the test difficulty. In contrast, the accelerated factor calculating in the proposed method is only dependent on specimen thickness, which would be easy to be conducted. Second, the AF of the temperature-dependent accelerated ageing method is limited due to the limitation of $T_{\mathrm{g}}$ of FRP composites, leading to the acceleration times being relatively small. The $A F$ of the proposed method is only dependent on specimen thickness and thus eliminates the limitation of $T_{\mathrm{g}}$. Therefore, greater $A F$ can be obtained in the proposed method. 


\section{Conclusions}

In this paper, the BFRP laminates with the thickness of $h=1, h=2$, and $h=4 \mathrm{~mm}$ were fabricated by wet-layup method and the influence of thickness on their water absorption and tensile properties were experimentally studied under hygrothermal environment as well as degradation mechanism. A specimen thickness-dependent accelerated ageing method was proposed. The following conclusions can be drawn from the testing results and discussions in this study:

The long-term properties of BFFRP laminates were greatly affected under hygrothermal environment. The water absorption trend of BFRP laminates soaked in both $60{ }^{\circ} \mathrm{C}$ deionized water and alkaline solution increased first before reaching their peak water absorption and then decreased with the increase of immersion duration, which was caused by the hydrolysis of the epoxy matrix. The tensile properties of BFRP laminates degraded apparently after ageing, especially in alkaline solution. SEM images show basalt fiber deteriorated due to the solution immersion.

Specimen thickness had a significant influence on the water absorption and tensile strength of BFRP laminates after ageing. When the BFRP laminates with different thicknesses were immersed in the water or alkaline solution for the same ageing time, the water absorption decreased in early stage of immersion and then increased in late stage of immersion as the specimen thickness increased, while the tensile strength retention kept increased during the whole ageing process. The reason is that the ratio of aged area to the total area in the thinner specimens was larger than that of the thicker specimens, leading to the more severe ageing degree of the thinner specimens.

An innovative thickness-dependent accelerated ageing method for water absorption and tensile strength retention of BFRP laminates was proposed, in which the accelerated factors were theoretically deduced based on specimen thickness. The proposed method is in good agreement with test results. Compared with the traditional accelerated ageing method based on temperature, the proposed method is much easier to be conducted and has the potential to obtain a greater accelerated factor.

Author Contributions: Conceptualization, Y.W.; methodology, Y.W. and X.Z.; software, W.Z.; validation, B.W., W.Z.; formal analysis, G.C.; investigation, G.C. and Y.W.; resources, Y.W.; data curation, W.Z.; writing-original draft preparation, W.Z.; writing-review and editing, Y.W., X.Z. and B.W.; visualization, G.C.; supervision, Y.W., X.Z. and G.C.; project administration, Y.W.; funding acquisition, Y.W. All authors have read and agreed to the published version of the manuscript.

Acknowledgments: The authors are grateful for the financial support from the National Key Research and Development Program of China (Project No. 2017YFC0703000), the National Natural Science Foundation of China (Project No. 51778102 and 51978126), the Fundamental Research Funds for the Central Universities of China (Project No. DUT18LK35), and the Natural Science Foundation of Liaoning Province of China (Project No. 20180550763).

Conflicts of Interest: The authors declare no conflict of interest.

\section{Abbreviations}

$\begin{array}{ll}\text { FRP } & \text { Fiber-reinforced polymer } \\ \text { BFRP } & \text { Basalt FRP } \\ \text { CFRP } & \text { Carbon FRP } \\ \text { GFRP } & \text { Glass FRP } \\ \text { AFRP } & \text { Aramid FRP } \\ \text { RC } & \text { reinforced concrete } \\ \text { VARI } & \text { vacuum assistant resin infusion } \\ \text { SEM } & \text { scanning electron microscopy } \\ \text { AF } & \text { accelerated factor }\end{array}$

\section{References}

1. Wei, Y.; Zhang, Y.; Chai, J.; Wu, G.; Dong, Z. Experimental investigation of rectangular concrete-filled fiber reinforced polymer (FRP)-steel composite tube columns for various corner radii. Compos. Struct. 2020, 244, 112311. [CrossRef] 
2. Bai, Y.L.; Dai, J.G.; Mohammadi, M.; Lin, G.; Mei, S.J. Stiffness-based design-oriented compressive stress-strain model for large-rupture-strain (LRS) FRP-confined concrete. Compos. Struct. 2019, 223, 110953. [CrossRef]

3. Wang, Y.; Cai, G.; Li, Y.; Waldmann, D.; Si Larbi, A.; Tsavdaridis, K.D. Behavior of circular fiber-reinforced polymer-steel-confined concrete columns subjected to reversed cyclic loads: Experimental studies and finite-element analysis. J. Struct. Eng. 2019, 145, 04019085. [CrossRef]

4. Zeng, J.; Gao, W.; Duan, Z.; Bai, Y.; Guo, Y.C.; Ouyang, L.J. Axial compressive behavior of polyethylene terephthalate/carbon FRP-confined seawater sea-sand concrete in circular columns. Constr. Build. Mater. 2020, 234, 117383. [CrossRef]

5. Cao, Q.; Tao, J.; Wu, Z.; Ma, Z.J. Behavior of FRP-Steel confined concrete tubular columns made of expansive self-consolidating concrete under axial compression. J. Compos. Constr. 2017, 21, 04017037-1-12. [CrossRef]

6. Bai, Y.L.; Yan, Z.W.; Ozbakkaloglu, T.; Han, Q.; Dai, J.G.; Zhu, D.J. Quasi-static and dynamic tensile properties of large-rupture-strain (LRS) polyethylene terephthalate fiber bundle. Constr. Build. Mater. 2020, 232, 117241. [CrossRef]

7. Wang, Y.; Wang, Y.; Han, B.; Wan, B.; Cai, G.; Chang, R. In situ strain and damage monitoring of GFRP laminates incorporating carbon nanofibers under tension. Polymers 2018, 10, 777. [CrossRef]

8. Cao, Q.; Li, H.; Lin, Z. Effect of active confinement on GFRP confined expansive concrete under axial cyclic loading. ACI Struct. J. 2020, 117, 207-216. [CrossRef]

9. Wang, Y.; Chen, G.; Wan, B.; Cai, G.; Zhang, Y. Behavior of circular ice-filled self-luminous FRP tubular stub columns under axial compression. Constr. Build. Mater. 2020, 232, 117287. [CrossRef]

10. Wei, Y.; Zhang, X.; Wu, G.; Zhou, Y. Behaviour of concrete confined by both steel spirals and fiber-reinforced polymer under axial load. Compos. Struct. 2018, 192, 577-591. [CrossRef]

11. Zhang, Y.; Wei, Y.; Bai, J.; Zhang, Y. Stress-strain model of an FRP-confined concrete filled steel tube under axial compression. Thin Walled Struct. 2019, 142, 149-159. [CrossRef]

12. Zhai, K.; Fang, H.; Fu, B.; Wang, F.; Hu, B. Mechanical response of externally bonded CFRP on repair of PCCPs with broken wires under internal water pressure. Constr. Build. Mater. 2020, 239, 117878. [CrossRef]

13. Wang, Y.; Wang, Y.; Wan, B.; Han, B.; Cai, G.; Li, Z. Properties and mechanisms of self-sensing carbon nanofibers/epoxy composites for structural health monitoring. Compos. Struct. 2018, 200, 669-678. [CrossRef]

14. Lu, M.; Xiao, H.; Liu, M.; Li, X.; Li, H.; Sun, L. Improved interfacial strength of SiO2 coated carbon fiber in cement matrix. Cem. Concr. Compos. 2018, 91, 21-28. [CrossRef]

15. He, J.; Xian, G.; Zhang, Y.X. Effect of moderately elevated temperatures on bond behaviour of CFRP-to-steel bonded joints using different adhesives. Constr. Build. Mater. 2020, 241, 118057. [CrossRef]

16. Li, J.; Xie, J.; Liu, F.; Lu, Z. A critical review and assessment for FRP-concrete bond systems with epoxy resin exposed to chloride environments. Compos. Struct. 2019, 229, 111372. [CrossRef]

17. Huang, H.; Jia, B.; Lian, J.; Wang, W. Experimental investigation on the tensile performance of resin-filled steel pipe splices of BFRP bars. Constr. Build. Mater. 2020, 242, 118018. [CrossRef]

18. Dong, Z.; Wu, G.; Xu, B.; Wang, X.; Taerwe, L. Bond durability of BFRP bars embedded in concrete under seawater conditions and the long-term bond strength prediction. Mater. Des. 2016, 92, 552-562. [CrossRef]

19. Li, Y.; Wang, Y.; Ou, J. Mechanical behavior of BFRP-steel composite plate under axial tension. Polymers. 2014, 6, 1862-1876. [CrossRef]

20. Wang, Y.; Wang, Y.; Wan, B.; Han, B.; Cai, G.; Chang, R. Strain and damage self-sensing of basalt fiber reinforced polymer laminates fabricated with carbon nanofibers/epoxy composites under tension. Compos. Part A Appl. Sci. Manuf. 2018, 113, 40-52. [CrossRef]

21. Dong, Z.; Wu, G.; Zhao, X.L.; Zhu, H.; Wei, Y.; Yan, Z. Mechanical properties of discrete BFRP needles reinforced seawater sea-sand concrete-filled GFRP tubular stub columns. Constr. Build. Mater. 2020, 244, 118330. [CrossRef]

22. Nguyen, V.D.; Hao, J.; Wang, W. Ultraviolet weathering performance of high-density polyethylene/wood-flour composites with a basalt-fiber-included shell. Polymers 2018, 10, 831. [CrossRef] [PubMed]

23. Wang, Z.; Zhao, X.L.; Xian, G.; Wu, G.; Singh Raman, R.K.; Al-Saadi, S. Durability study on interlaminar shear behaviour of basalt-, glass- and carbon-fibre reinforced polymer (B/G/CFRP) bars in seawater sea sand concrete environment. Constr. Build. Mater. 2017, 156, 985-1004. [CrossRef]

24. Quagliarini, E.; Monni, F.; Bondioli, F.; Lenci, S. Basalt fiber ropes and rods: Durability tests for their use in building engineering. J. Build. Eng. 2016, 5, 142-150. [CrossRef] 
25. Li, S.; Hu, J.; Ren, H. The combined effects of environmental conditioning and sustained load on mechanical properties of wet lay-up fiber reinforced polymer. Polymers 2017, 9, 244. [CrossRef]

26. Sharma, B.; Chhibber, R.; Mehta, R. Seawater ageing of glass fiber reinforced epoxy nanocomposites based on silylated clays. Polym. Degrad. Stab. 2018, 147, 103-114. [CrossRef]

27. Jiang, X.; Luo, C.; Qiang, X.; Zhang, Q.; Kolstein, H.; Bijlaard, F. Coupled hygro-mechanical finite element method on determination of the interlaminar shear modulus of glass fiber-reinforced polymer laminates in bridge decks under hygrothermal aging effects. Polymers 2018, 10, 845. [CrossRef]

28. Lu, Z.; Xian, G.; Li, H. Effects of thermal aging on the water uptake behavior of pultruded BFRP plates. Polym. Degrad. Stab. 2014, 110, 216-224. [CrossRef]

29. Lu, Z.; Xian, G.; Li, H. Effects of exposure to elevated temperatures and subsequent immersion in water or alkaline solution on the mechanical properties of pultruded BFRP plates. Compos. Part B Eng. 2015, 77, 421-430. [CrossRef]

30. Ma, G.; Yan, L.; Shen, W.; Zhu, D.; Huang, L.; Kasal, B. Effects of water, alkali solution and temperature ageing on water absorption, morphology and mechanical properties of natural FRP composites: Plant-based jute vs. mineral-based basalt. Compos. Part B Eng. 2018, 153, 398-412. [CrossRef]

31. Xiao, B.; Li, H.; Xian, G. Hygrothermal ageing of basalt fiber reinforced epoxy composites. In Advances in FRP Composites in Civil Engineering, Proceedings of the 5th International Conference on FRP Composites in Civil Engineering, CICE 2010, Beijing, China, 27-29 September 2010; Springer: Berlin/Heidelberg, Germany, 2011; pp. 356-359.

32. Wu, G.; Wang, X.; Wu, Z.; Dong, Z.; Zhang, G. Durability of basalt fibers and composites in corrosive environments. J. Compos. Mater. 2015, 49, 873-887. [CrossRef]

33. Li, X.; Yahya, M.Y.; Nia, A.B.; Wang, Z.; Yang, J.; Lu, G. Dynamic failure of basalt/epoxy laminates under blast-Experimental observation. Int. J. Impact Eng. 2017, 102, 16-26. [CrossRef]

34. Benmokrane, B.; Manalo, A.; Bouhet, J.C.; Mohamed, K.; Robert, M. Effects of diameter on the durability of glass fiber-reinforced polymer bars conditioned in alkaline solution. J. Compos. Constr. 2017, 21, 04017040. [CrossRef]

35. Wu, G.; Wang, X.; Wu, Z.; Dong, Z.; Xie, Q. Degradation of basalt FRP bars in alkaline environment. Sci. Eng. Compos. Mater. 2015, 22, 649-657. [CrossRef]

36. Chen, Y.; Davalos, J.F.; Ray, I. Durability prediction for GFRP reinforcing bars using short-term data of accelerated aging tests. J. Compos. Constr. 2006, 10, 279-286. [CrossRef]

37. Wang, Z.; Xian, G.; Zhao, X.L. Effects of hydrothermal aging on carbon fibre/epoxy composites with different interfacial bonding strength. Constr. Build. Mater. 2018, 161, 634-648. [CrossRef]

38. Wang, Y.; Cai, G.; Si Larbi, A.; Waldmann, D.; Tsavdaridis, K.D.; Ran, J. Monotonic axial compressive behaviour and confinement mechanism of square CFRP-steel tube confined concrete. Eng. Struct. 2020, in press.

39. ASTM International. Standard Test Method for Moisture Absorption Properties and Equilibrium Conditioning of Polymer Matrix Composite Materials (ASTM D5229/D5229-14); ASTM International: West Conshohocken, PA, USA, 2014.

40. American Concrete Institute. Guide Test Methods for Fiber-Reinforced Polymers (FRPs) for Reinforcing or Strengthening Concrete Structures; A.C.I. Committee 440, Report 440.3R-12; American Concrete Institute: Farmington Hills, MI, USA, 2012.

41. ASTM International. Standard Test Method for Tensile Properties of Polymer Matrix Composite Materials (ASTM D3039/D3039M-14); ASTM International: West Conshohocken, PA, USA, 2014.

42. Hong, B.; Xian, G.; Wang, Z. Durability study of pultruded carbon fiber reinforced polymer plates subjected to water immersion. Adv. Struct. Eng. 2018, 21, 571-579. [CrossRef]

43. Agwa, M.A.; Taha, I.; Megahed, M. Experimental and analytical investigation of water diffusion process in nano-carbon/alumina/silica filled epoxy nanocomposites. Int. J. Mech. Mater. Des. 2017, 13, 607-615. [CrossRef]

44. Almeida, J.H.S.; Souza, S.D.B.; Botelho, E.C.; Amico, S.C. Carbon fiber-reinforced epoxy filament-wound composite laminates exposed to hygrothermal conditioning. J. Mater. Sci. 2016, 51, 4697-4708. [CrossRef]

45. Chin, J.W.; Nguyen, T.; Aouadi, K. Sorption and Diffusion of water, salt water, and concrete. J. Appl. Polym. Sci. 1999, 71, 483-492. [CrossRef] 
46. Garg, M.; Sharma, S.; Mehta, R. Carbon nanotube-reinforced glass fiber epoxy composite laminates exposed to hygrothermal conditioning. J. Mater. Sci. 2016, 51, 8562-8578. [CrossRef]

47. Wang, Z.; Zhao, X.L.; Xian, G.; Wu, G.; Singh Raman, R.K.; Al-Saadi, S.; Haque, A. Long-term durability of basalt- and glass-fibre reinforced polymer (BFRP/GFRP) bars in seawater and sea sand concrete environment. Constr. Build. Mater. 2017, 139, 467-489. [CrossRef]

48. Shi, J.; Wang, X.; Wu, Z.; Zhu, Z. Fatigue behavior of basalt fiber-reinforced polymer tendons under a marine environment. Constr. Build. Mater. 2017, 137, 46-54. [CrossRef]

49. Hojo, H.; Tsuda, K.; Ogasawara, K. Form and rate of corrosion of corrosion-resistant FRP resins. Adv. Compos. Mater. 1991, 1, 55-67. [CrossRef]

50. Bao, L.R.; Yee, A.F. Effect of temperature on moisture absorption in a bismaleimide resin and its carbon fiber composites. Polymer 2002, 43, 3987-3997. [CrossRef]

51. Satterfleld, M.B.; Benziger, J.B. Non-Fickian water vapor sorption dynamics by nafion membranes. J. Phys. Chem. B 2008, 112, 3693-3704. [CrossRef]

52. Zhang, X.; Wang, Y.; Wan, B.; Cai, G.; Qu, Y. Effect of specimen thicknesses on water absorption and flexural strength of CFRP laminates subjected to water or alkaline solution immersion. Constr. Build. Mater. 2019, 208, 314-325. [CrossRef]

53. Wang, Y.; Zhang, X.; Cai, G.; Wan, B.; Waldmann, D.; Qu, Y. A new thickness-based accelerated aging test methodology for resin materials: Theory and preliminary experimental study. Constr. Build. Mater. 2018, 186, 986-995. [CrossRef]

54. Pi, Z.; Xiao, H.; Du, J.; Liu, M.; Li, H. Interfacial microstructure and bond strength of nano-SiO2-coated steel fibers in cement matrix. Cem. Concr. Compos. 2019, 103, 1-10. [CrossRef]

55. Phani, K.K.; Bose, N.R. Hydrothermal ageing of CSM-laminate during water immersion-An acoustoultrasonic study. J. Mater. Sci. 1986, 21, 3633-3637. [CrossRef]

56. Li, C.; Xian, G.; Li, H. Effect of postcuring immersed in water under hydraulic pressure on fatigue performance of large-diameter pultruded carbon/glass hybrid rod. Fatigue Fract. Eng. Mater. Struct. 2019, 42, 1148-1160. [CrossRef]

(C) 2020 by the authors. Licensee MDPI, Basel, Switzerland. This article is an open access article distributed under the terms and conditions of the Creative Commons Attribution (CC BY) license (http://creativecommons.org/licenses/by/4.0/). 